\title{
UCRL-JRNL-226089
}

LAW RENCE LIVERMORE N A T IO N A L LABORATORY
Detailed Chemical Kinetic Modeling of Cyclohexane Oxidation

E. J. Silke, W. J. Pitz, C. K. Westbrook, M. Ribaucour

November 14, 2006

Journal of Physical Chemistry A 
This document was prepared as an account of work sponsored by an agency of the United States Government. Neither the United States Government nor the University of California nor any of their employees, makes any warranty, express or implied, or assumes any legal liability or responsibility for the accuracy, completeness, or usefulness of any information, apparatus, product, or process disclosed, or represents that its use would not infringe privately owned rights. Reference herein to any specific commercial product, process, or service by trade name, trademark, manufacturer, or otherwise, does not necessarily constitute or imply its endorsement, recommendation, or favoring by the United States Government or the University of California. The views and opinions of authors expressed herein do not necessarily state or reflect those of the United States Government or the University of California, and shall not be used for advertising or product endorsement purposes. 


\section{Detailed Chemical Kinetic Modeling of}

\section{Cyclohexane Oxidation}

Emma J. Silke*, William J. Pitz, Charles K. Westbrook and Marc Ribaucour ${ }^{\dagger}$.

Lawrence Livermore National Laboratory, California 94550, USA.

†UMR 8522 Physicochimie des Processus de la Combustion, LC3 Laboratoire de Cinetique et Chimie de la Combustion,

Université des Sciences et Technologies de Lille,

Bâtiment C11, 59655 Villeneuve d'Ascq, France

*silke2@1ln1.gov

\section{RECEIVED DATE (to be automatically inserted after your manuscript is accepted if required according to the journal that you are submitting your paper to)}

\footnotetext{
ABSTRACT A detailed chemical kinetic mechanism has been developed and used to study the oxidation of cyclohexane at both low and high temperatures. Reaction rate constant rules are developed for the low temperature combustion of cyclohexane. These rules can be used for in chemical kinetic mechanisms for other cycloalkanes. Since cyclohexane produces only one type of cyclohexyl radical, much of the low temperature chemistry of cyclohexane is described in terms of one potential energy diagram showing the reaction of cyclohexyl radical $+\mathrm{O}_{2}$ through
} 
five, six and seven membered ring transition states. The direct elimination of cyclohexene and $\mathrm{HO}_{2}$ from $\mathrm{RO}_{2}$ is included in the treatment using a modified rate constant of Cavallotti et al. Published and unpublished data from the Lille rapid compression machine, as well as jet-stirred reactor data are used to validate the mechanism. The effect of heat loss is included in the simulations, an improvement on previous studies on cyclohexane. Calculations indicated that the production of 1,2-epoxycyclohexane observed in the experiments can not be simulated based on the current understanding of low temperature chemistry. Possible 'alternative' H-atom isomerisations leading to different products from the parent $\mathrm{O}_{2} \mathrm{QOOH}$ radical were included in the low temperature chemical kinetic mechanism and were found to play a significant role.

KEYWORDS Cyclohexane, kinetic modeling, oxidation, low temperature

INTRODUCTION Cycloalkanes are an important chemical class of hydrocarbons found in Diesel, jet and gasoline fuels. As the price of crude oil rises, Canada's oil-sand reserves are fast becoming an attractive source of synthetic crude oil. Canada's oil-sand reserves are second only to Saudi Arabia's reserves in proven oil reserves ${ }^{1}$. With the emergence of oil-sand derived fuels, their role will become more important in future transportation fuels. Diesel fuel derived from oilsands is expected to have a higher cycloalkane content which will affect the ignition quality of the fuel and soot emissions from its use in a Diesel-fueled cars and trucks. As a result, the effect of the composition of these oil-sand derived fuels on combustion in vehicles is of immediate interest. As well as being expected to be present in large amounts in Diesel fuel derived from oilsands, cycloalkanes are a significant component of conventional Diesel fuel (up to approximately $35 \%)$, jet fuels $(\sim 20 \%)$ and gasoline $(\sim 10 \%)^{2,3}$. Cycloalkanes can raise soot emission levels because they are known to dehydrogenate and produce aromatics which can lead 
to the production of polycyclic aromatics that are thought to be inception sites for soot growth ${ }^{4-6}$. As such, validated chemical kinetic mechanisms for cycloalkanes are needed to treat the oxidation of cycloalkanes under engine conditions.

Diesel, gasoline, jet and oil-sand derived fuels are complex mixtures of hundreds to thousands of hydrocarbons. It is not computationally feasible to include all these components in a model with detailed chemistry. Therefore, chemical kinetic models with a limited number of components (called surrogate fuel models) are presently used to treat these practical fuels. Generally, one or two components from each chemical class (n-alkanes, iso-alkanes, cycloalkanes, alkenes and aromatics) are selected to represent these chemical classes in a surrogate fuel. Because of the high proportion of cycloalkanes in practical fuels, detailed mechanisms for cycloalkanes are needed to simulate this chemical class. These mechanisms need to be valid under conditions found in internal combustion engines so that when they are inserted into surrogate fuel models they can be used to simulate combustion in spark ignition, homogeneous charge compression ignition (HCCI), Diesel and jet engines. Such surrogate fuel models are valuable in optimizing the design and performance for these engines and minimizing their pollutant emissions ${ }^{7}$.

To begin the development of chemical kinetic models for cycloalkanes, we have started with cyclohexane, the simplest of cycloalkanes. We have chosen cyclohexane because considerably more experimental data is available for cyclohexane compared to other cycloalkanes. Also, because of its simplicity, it is a good starting case for the development of reaction rate rules for cycloalkanes. These reaction rate rules can be used later in the development of mechanisms for larger cycloalkanes that are more representative of component present in Diesel and jet fuels. In 
this paper, we focus on the low and intermediate temperature chemistry of cyclohexane because the prediction of this chemistry is critical for correct simulation of ignition in HCCI and Diesel engines.

PREVIOUS CYCLOHEXANE STUDIES There have been many chemical kinetic studies of oxidation of $n$-alkanes and branched alkanes in recent years ${ }^{8}$. There are considerably fewer comparable studies of kinetics of cycloalkanes in general and cyclohexane in particular, but they cover a rather wide range of experimental conditions. Cyclohexane kinetics have been examined experimentally in shock tubes ${ }^{9,10}$, in the rapid compression machine $(\mathrm{RCM})^{11}$, in the jet-stirred reactor $(\mathrm{JSR})^{12,13}$, in a plug flow reactor ${ }^{14}$, in closed reactors ${ }^{5,6,15-19}$ and in laminar premixed ${ }^{4}$ and non-premixed flames ${ }^{20,21}$. General features of cyclohexane oxidation, based on this work, are that cyclohexane oxidation at high temperatures can take place through several distinct reaction pathways, including unimolecular decomposition of cyclohexane leading to linear products, and $\mathrm{H}$-atom abstraction leading both to dehydrogenation and formation of benzene and to $\beta$-scission reactions that break the cyclic ring. The relative importance of each of these pathways varied widely from one oxidation environment to another.

At lower temperatures, addition of molecular oxygen to cyclohexyl radicals is generally observed, followed by internal $\mathrm{H}$-atom transfer reactions and other pathways leading to a negative temperature coefficient (NTC) region similar to those observed in many $n$-alkane and iso-alkane hydrocarbon fuels. The only available experimental data on cyclohexane ignition across the NTC region from $700-850 \mathrm{~K}$ were reported by Lemaire et al. ${ }^{11}$, and these data have been used by all subsequent kinetic modeling programs to validate the low temperature portions of their reaction mechanisms. 
Recently, kinetic modeling studies of cyclohexane oxidation have begun to appear, with both high temperature $9,10,13$ and combined high and low temperature ${ }^{22-24}$ reaction mechanisms being developed.

Several major issues have been identified in past publications and are still not completely resolved, and one goal of the present paper is to address these issues. Dehydrogenation of cyclohexane to produce benzene is potentially important as a pathway leading to soot formation that is distinct from the more familiar routes that require aromatic ring formation by reactions involving $\mathrm{C}_{3} \mathrm{H}_{3}, \mathrm{C}_{4} \mathrm{H}_{5}$ and similar smaller species ${ }^{25}$. Some of the cyclohexane studies have observed the cyclohexa-1,3-diene and benzene products of this reaction path ${ }^{4,5,11-12,26}$ while others ${ }^{20}$ have not.

There are two interesting questions regarding possible distinctions between classes of reactions in cyclic alkanes and the same classes of reactions in $n$-alkane and iso-alkane species. The major pathway for consumption of cyclohexane is $\mathrm{H}$-atom abstraction by radicals, especially by $\mathrm{H}, \mathrm{OH}$ and $\mathrm{HO}_{2}$. The $\mathrm{C}-\mathrm{H}$ bonds in cyclohexane are quite similar to secondary $\mathrm{C}-\mathrm{H}$ bonds in $n$-alkanes such as $n$-heptane, so some kinetics researchers have assumed that the rates of $\mathrm{H}$-atom abstraction in cyclohexane should be very close to the rates of secondary H-atom abstraction in n-heptane. The limits of such assumptions should be assessed.

In addition, in the low temperature regime, the most sensitive reactions determining the rate of autoignition in acyclic alkanes such as $n$-heptane ${ }^{27}$ or iso-octane ${ }^{28}$ involve internal H-atom transfers in $\mathrm{RO}_{2}$ and $\mathrm{O}_{2} \mathrm{QOOH}$ species. The same types of species are observed in low 
temperature ignition of cyclohexane, including cyclohexyl- $\mathrm{O}_{2}$ and $\mathrm{O}_{2} \mathrm{QOOH}$ species, but an important question is how to estimate the rates of these reactions. In a recent kinetic modeling study of methylcyclohexane autoignition by Pitz et $a{ }^{29}$, it was found that the presence of the cyclic ring contributes to the activation energy barriers for these isomerisation reactions, and the recent study of Buda et al. ${ }^{22,23}$ reached the same conclusion for cyclohexane.

A goal of the present paper is to determine the similarities and differences in the correction terms between cyclic and acyclic isomerisation reactions in order to establish a formula for future mechanism development in other cyclic hydrocarbon species.

CHEMICAL KINETIC MECHANISM The kinetic mechanism used in this study was developed by adding all the species and reactions relating to the low and high temperature chemistry of cyclohexane (CHX), to the previously developed and validated mechanisms for $\mathrm{C}_{1}-\mathrm{C}_{6}{ }^{28}$, which has been constructed as a hierarchy of sequential hydrocarbon-oxygen systems. Submechanisms for toluene, benzene, cyclopentadiene and the most recently published mechanism for methylcyclohexane were also included ${ }^{29,30}$. Reaction paths for cyclohexane were delineated and reaction rate constants for both low and high temperature oxidation of cyclohexane were estimated, or assembled using data the literature. The THERM program of Ritter and Bozzelli ${ }^{31,32}$ which uses the group additivity methods of Benson ${ }^{33}$ was used to evaluate thermodynamic properties for all the chemical species, including stable molecules and relevant radicals. The chemical kinetic mechanism and thermochemical property files are available as supplemental data. 
The mechanism development in the current work concerned both high and low temperature chemistry for cyclohexane, which includes all the reactions known to be pertinent for these temperature regimes. At high temperatures, the reactions include unimolecular fuel decomposition, $\mathrm{H}$-atom abstraction, alkyl radical decomposition and addition to $\mathrm{O}_{2}$, as well as isomerisation reactions are known to be important. Indeed, the well documented formation of benzene via the dehydrogenation of cyclohexane is included and noted in later discussion. The dehydrogenation of cyclohexane forms cyclohexene, which in turn can form cyclohexa-1,3-diene (and to a lesser extent, cyclohexa-1,4-diene) and then benzene, Figure 1. For fuel rich mixtures, benzene can lead to polycyclic aromatic hydrocarbons that are currently thought to act as sites for soot inception. Therefore, properly predicting the amount of benzene formed is an important step toward prediction of soot formation from cyclohexane.

At lower temperatures, the dominant reaction path for cyclohexane is $\mathrm{H}$-atom abstraction from the parent fuel molecule by $\mathrm{OH}, \mathrm{HO}_{2}$ and other radicals, followed by successive additions of oxygen leading to chain branching pathways, through the well established low temperature reaction scheme ${ }^{27}$. This scheme follows the addition of the cyclohexyl radicals, $(\mathrm{R})$, to $\mathrm{O}_{2}$ and subsequent reactions, including cyclohexylperoxy $\left(\mathrm{RO}_{2}\right)$ isomerisation to hydroperoxycyclohexyl radicals (QOOH) and decomposition of $\mathrm{QOOH}$ to cyclic ethers as well as other products.

Hydroperoxy-cyclohexyl radicals $(\mathrm{QOOH})$ can also add to $\mathrm{O}_{2}$ resulting in $\mathrm{O}_{2} \mathrm{QOOH}$, which can then isomerize to give carbonyl-hydroperoxide (or 'keto-hydroperoxide') species and a hydroxyl radical. This carbonyl-hydroperoxide can decompose and yield a second hydroxyl radical. 
In the next section, we discuss specific classes of elementary reactions and their rate constant determination. We discuss the most important reactions consuming the fuel and the subsequent reaction pathways.

REACTION RATE CONSTANT DETERMINATION In the following section, the rate rules employed for initiation reactions (including unimolecular fuel decomposition and molecular elimination reactions), followed by $\mathrm{H}$-atom abstraction from the fuel, alkyl radical decomposition, alkyl radical isomerisation and alkyl radical consumption as well as the subsequent reaction classes pertinent to the low temperature regime are discussed.

Unimolecular fuel decomposition for cyclohexane can initiate through bond homolysis on the six-membered ring which leads to the formation of a $\mathrm{C}_{6} \mathrm{H}_{12}$ diradical. The rate constant for this reaction class was specified by a reverse recombination rate constant of $1.0 \times 10^{8} \mathrm{~T}^{0.86}$. This rate constant was analogous to the rate constant employed in the methylcyclohexane mechanism of Orme et al. ${ }^{34}$ for carbon radical-radical recombination, resulting in the formation of a ring structure. Our rate constant is approximately 1.4 times faster than that used by Sirjean et al. ${ }^{9}$ for unimolecular initiation reaction of cyclohexane resulting in a diradical.

Molecular elimination reactions for cyclohexane were included such that the parent fuel could eliminate either two propane molecules, or three ethane molecules. The rate constants for both these reactions were assumed to be the same as 1-hexene eliminating two propene molecules, using the Tsang ${ }^{35}$ rate constant expression of $4.0 \times 10^{12} \exp (-57400 \mathrm{cal} / \mathrm{RT}) \mathrm{cm}^{3} \mathrm{~mol}^{-1} \mathrm{~s}^{-1}$. 
In cyclohexane all the sites available for hydrogen atom abstraction are equivalent, since abstraction is always from a secondary site embedded in a ring structure. The environment of such a ring-bound $2^{\circ} \mathrm{H}$-atom is somewhat different to a normal $2^{\circ} \mathrm{H}$-atom. For abstraction by $\mathrm{H}$, $\mathrm{O}, \mathrm{OH}, \mathrm{CH}_{3}, \mathrm{CH}_{3} \mathrm{O}, \mathrm{C}_{2} \mathrm{H}_{3}$ and $\mathrm{C}_{2} \mathrm{H}_{5}$ of $2^{\circ} \mathrm{C}-\mathrm{H}$ bonds we assumed the rate constant to be similar to that of a normal $2^{\circ} \mathrm{H}$-atom and employed the recommended rates of Curran et al ${ }^{28}$ For Hatom abstraction by $\mathrm{HO}_{2}$ we used a cyclohexane specific rate, determined by Handford-Styring and Walker ${ }^{6}$ in their study of $\mathrm{H}$-atom abstraction by $\mathrm{HO}_{2}$ from $2^{\circ} \mathrm{C}-\mathrm{H}$ sites in cyclohexane. The rate employed for $\mathrm{H}$-atom abstraction by $\mathrm{HO}_{2}$ was $1.12 \times 10^{5} \mathrm{~T}^{2.5} \exp (-14147 \mathrm{cal} / \mathrm{RT}) \mathrm{cm}^{3} \mathrm{~mol}^{-1}$ $\mathrm{s}^{-1}$. For abstraction by $\mathrm{CH}_{3} \mathrm{O}_{2}$ and cycloalkylperoxy radical we assumed that the rate constant was the same as the analogous reaction of $\mathrm{HO}_{2}$ abstraction of a $2^{\circ} \mathrm{H}$-atom, as reported by Scott and Walker ${ }^{36}$, such that rate expression used for both these reactions was $1.47 \times 10^{5} \mathrm{~T}^{2.5} \exp (-$ $14863 \mathrm{cal} / \mathrm{RT}) \mathrm{cm}^{3} \mathrm{~mol}^{-1} \mathrm{~s}^{-1}$.

Rate constants for Alkyl radical decomposition were specified in the reverse, exothermic direction, that is the addition of an alkyl radical to an alkene. Rate constant for the addition of radicals to a double bond depends on a number of factors: namely, the type of radical undergoing to addition, as well as the nature of the site to which it is adding - an internal or terminal $\mathrm{C}$ atom. The rate expressions used were taken from the recent work of Curran ${ }^{37}$ who evaluated rate constants for $\mathrm{C}_{1}-\mathrm{C}_{4}$ alkyl and alkoxyl radical decomposition. In our rate constant estimations, we considered the type (primary, secondary, or tertiary) and size of alkyl radical, as well as the type of site (internal or terminal) on the alkene the radical was adding to.

In the case of ring opening reactions, for species with radical sites on the $\mathrm{C}_{6}$ ring, rate constants were estimated in the reverse direction. An example of a ring opening reaction is 
illustrated as Step A in Figure 2. The reverse of Step A is a methyl radical adding to the terminal group of an olefin forming a cyclic structure. Rate constants for such reactions were taken from Matheu et al. ${ }^{38}$ who reviewed and estimated high pressure rate constants for these reactions. For example, the rate constant used for the endo, 1,6-intramolecular addition in Figure 2 was $1.00 \mathrm{x}$ $10^{8} \mathrm{~T}^{0.86} \exp (-5900 \mathrm{cal} / \mathrm{RT}) \mathrm{cm}^{3} \mathrm{~mol}^{-1} \mathrm{~s}^{-1}$.

The rate constants used for alkyl radical isomerisation in this study are taken from Matheu et $a l .{ }^{38}$ who used high level quantum calculations (B3LYP-ccpVDZ) for such isomerisations or 'Hshifts'. For example, the isomerisation in Figure 2 illustrates a 1,4 $\mathrm{H}$ shift (5-membered transition state) of a primary radical shifting to an allylic radical site with a rate expression of $3.67 \times 10^{12} \mathrm{~T}^{-0.6} \exp (-15300 \mathrm{cal} / \mathrm{RT}) \mathrm{cm}^{3} \mathrm{~mol}^{-1} \mathrm{~s}^{-1}$.

LOW TEMPERATURE CHEMISTRY SCHEME Reaction rate constants for the low temperature oxidation of cyclohexane were developed based on those previously developed for methylcyclohexane ${ }^{29}$. In particular, Pitz et al. reported that the use of non-cyclic alkylperoxy isomerisation rates led to a dominance of 7-membered ring isomerisations which lead to chain propagation channels as opposed to the chain-branching paths associated with 6-membered rings, and attributed this dominance to the lack of low temperature chain branching for methylcyclohexane. They subsequently showed the use of cyclo-specific rate rules were necessary to simulate the experimental data for cyclic systems and such specifics will be discussed here according to reaction class.

The first step in the low temperature chemistry scheme is illustrated in Figure 3, where the potential energy diagram for the addition of molecular oxygen to the cyclohexyl radical is 
depicted. Conveniently, cyclohexane has only one isomer. Since such an addition of molecular oxygen is dependent on the nature of the radical site where the addition is to occur, the rate constant applied was based on an analogy of that used in the methylcyclohexane paper ${ }^{29}$, for addition to a secondary alkyl radical, $3.0 \times 10^{12} \mathrm{~cm}^{3} \mathrm{~mol}^{-1} \mathrm{~s}^{-1}$.

The next step in the low temperature reaction scheme is alkylperoxy isomerisation. In this work, we have employed the rate constants used in the methylcyclohexane study of Pitz et al. ${ }^{29}$. They used the non-cyclic alkylperoxy isomerisation rate recommendations of Curran et al. ${ }^{28}$, Table 1, and corrected them for the cyclohexyl case. The corrections they employed were taken from the $n$-alkane and specific cyclohexane rate constants of Walker and coworkers ${ }^{5,6}$ where kinetic data for $\mathrm{H}$-atom transfer in cyclohexylperoxy radical $\left(\mathrm{CHXO}_{2}\right)$, was compared to kinetic data Walker and coworkers had previously published for non-cyclic alkylperoxy radicals ${ }^{39}$. The details of the modification are shown in Table 1, where the kinetic data in use in this study are reported.

Recent studies, including that of Carstensen et al. ${ }^{41}$ on $n$-alkanes such as ethane and propane have highlighted the importance of the direct elimination of olefin and a hydroperoxyl from $\mathrm{RO}_{2}$. We included the direct elimination pathway in our cyclohexane mechanism and found ignition delay times to be highly sensitive to rate expression in use for this reaction. We employed the rate constant computed by Cavallotti et al. ${ }^{23}$, where we have reduced the A-factor by a factor of 2 such that the expression in use is $3.85 \times 10^{12} \exp (-29000 \mathrm{cal} / \mathrm{RT}) \mathrm{cm}^{3}-\mathrm{mol}^{-1}-\mathrm{s}^{-1}$.

In addition, we employ slightly modified versions of the Cavallotti recommendations for the formation of cyclic ether and a hydroxyl radical from $\mathrm{QOOH}$ radicals, Table 2. These rate 
constant modifications were necessary for agreement with experiments, and a reduction in activation energy from the Cavallotti value to those in use in Table 2 gave good agreement between the model and experiment for both 1,3- and 1,4-epoxycyclohexane. However, we were unable to match the experimental profile of 1,2-epoxycyclohexane (cyclic ether ring size 3) even after increasing the A factor by a factor of 2 and reduced the activation barrier from 15.4 to 13.4 kcal $\mathrm{mol}^{-1}$.

Hydroperoxy-cyclohexyl $(\mathrm{QOOH})$ radicals, where the radical site is located beta to the hydroperoxy group, may decompose to yield a conjugate olefin and $\mathrm{HO}_{2}$ radical. The rate constant for this reaction was considered in the reverse direction, that is, the addition of a $\mathrm{HO}_{2}$ radical to an olefinic site. We employed a rate constant of $8.0 \times 10^{10} \exp (-6000 \mathrm{cal} / \mathrm{RT}) \mathrm{cm}^{3}-\mathrm{mol}^{-}$ ${ }^{1}-\mathrm{s}^{-1}$, similar to that used in the methylcyclohexane study of Pitz et al. ${ }^{29}$

Finally, QOOH radicals can $\beta$-scission to form a multitude of products. For the hydroperoxycyclohexyl radicals this always involves a ring opening step initially, and subsequent $\beta$-scission to radical and a stable intermediate species. We carefully considered the decomposition pathways of each QOOH radical in the mechanism.

Disproportionation reactions between radicals important at low temperature must be considered:
a. $\mathrm{R}+\mathrm{HO}_{2}=\mathrm{RO}+\mathrm{OH}$
b. $\mathrm{RO}_{2}+\mathrm{HO}_{2}=\mathrm{RO}_{2} \mathrm{H}+\mathrm{O}_{2}$
c. $\mathrm{RO}_{2}+\mathrm{CH}_{3} \mathrm{O}_{2}=\mathrm{RO}+\mathrm{CH}_{3} \mathrm{O}+\mathrm{O}_{2}$
d. $\mathrm{RO}_{2}+\mathrm{R}^{\prime} \mathrm{O}_{2}=\mathrm{RO}+\mathrm{R}^{\prime} \mathrm{O}+\mathrm{O}_{2}$ 
For each if these reactions, the rate rules proposed by Curran et al. in their iso-octane paper are employed $^{28}$.

For $\mathrm{ROOH}$ dissociation, the rate constant was considered in the reverse direction, and based on an analogy with the reaction of $\mathrm{CH}_{3} \mathrm{O}+\mathrm{OH}$ by Tsang ${ }^{42}$, so that we use $1.81 \times 10^{13} \mathrm{~cm}^{3} \mathrm{~mol}^{-1} \mathrm{~s}^{-1}$. In the decomposition of RO, and since a cyclic system is in question here, initially there is a ring opening step followed by $\beta$-scission forming products. As per our regular rules, and as described earlier, we consider this ring opening step in the reverse direction and use $1.00 \times 10^{8} \mathrm{~T}^{0.86} \exp (-$ $5900 \mathrm{cal} / \mathrm{RT}) \mathrm{cm}^{3} \mathrm{~mol}^{-1} \mathrm{~s}^{-1}$, the Matheu et al. ${ }^{38}$ recommendation for 1,6-intramolecular addition (endo).

For the addition of $\mathrm{QOOH}$ to $\mathrm{O}_{2}$ the rate expressions used were identical to for cyclohexyl addition to $\mathrm{O}_{2}$ discussed earlier in this paper. The resulting species, $\mathrm{O}_{2} \mathrm{QOOH}$, can isomerize to form a carbonyl-hydroperoxide and a hydroxyl radical. The rate constant for this, as well as for other isomerisations via an internal hydrogen atom, which result in what we term 'alternative' $\mathrm{O}_{2} \mathrm{QOOH}$, are analogous to those for $\mathrm{RO}_{2}$ isomerizing to QOOH. For $\mathrm{O}_{2} \mathrm{QOOH}$ isomerisation to carbonyl-hydroperoxide and a hydroxyl radical, the rate expressions used were based on the recommendations of Curran et al. ${ }^{28}$ and are reported in Table 3. However, as with the non-cyclic alkylperoxy isomerisations, the rate we use for this cyclic $\mathrm{O}_{2} \mathrm{QOOH}$ isomerisation is modified to account for the ring structure. As with the previous studies of Curran et al. on $n$-heptane ${ }^{27}$ and iso-octane $\mathrm{e}^{28}$, the activation energy was reduced by $3 \mathrm{kcal} \mathrm{mol}^{-1}$ since the hydrogen atom being abstracted is bound to a carbon atom which is bound to a hydroperoxy group and should in turn be more easily removed. 


\section{'Alternative' $\mathrm{O}_{2} \mathrm{QOOH}$}

In the previous studies on $n$-heptane and iso-octane by Curran et al. ${ }^{27,28}$, only one internal $\mathrm{H}$ atom isomerisation step for $\mathrm{O}_{2} \mathrm{QOOH}$ was considered, such that the products were always a stable carbonyl-hydroperoxide species and a hydroxyl radical, Figure 4, and this was based on experimental observations available at the time.

At that time, Curran et al. also argued that for this particular $\mathrm{H}$-atom isomerisation, the $\mathrm{C}-\mathrm{H}$ bond strength is weaker than a typical $\mathrm{H}$-atom in a hydrocarbon species and thus more easily abstracted. However, ring-strain energies dictate that in many instances other conventional hydrogen atoms, which may form 5-, 6- or 7- membered transitions states, are also available. Thus, $\mathrm{O}_{2} \mathrm{QOOH}$ can also isomerize to form what we term 'alternative' $\mathrm{O}_{2} \mathrm{QOOH}$, which can then ultimately decompose to a different set of products. Rate constant analysis for cyclohexane has shown that these alternative reactions are indeed competitive with the formation of the carbonylhydroperoxide and a hydroxyl radical. For this reason, the possibility of such 'alternative' isomerisations occurring, leading to different products from the parent $\mathrm{O}_{2} \mathrm{QOOH}$ are permitted and included in this work on cyclohexane, along with the more conventional route forming carbonyl-hydroperoxide and a hydroxyl radical. An example of the alternative isomerisation is illustrated in Figure 5, and Table 3 documents the reaction rates used in this work. Some interesting observations were made in relation to the sensitivity of including this additional low temperature chemistry, and these are reported and discussed in detail in the Results section of this paper. 


\section{RESULTS AND DISCUSSION}

In order to validate this mechanism it was necessary to carry out simulations of experiments reported in the literature. In this following section we describe how the mechanism developed in this work was used to simulate experimental results obtained in a rapid compression machine $(\mathrm{RCM})^{11}$ and in a jet stirred reactor $(\mathrm{JSR})^{12,13}$. The RCM study incorporated the range of temperatures at which negative temperature coefficient behavior is observed in the oxidation of cyclohexane.

\section{Rapid Compression Machine}

The experiments of Lemaire et al. ${ }^{11}$ were conducted in a rapid compression machine at a compression ratio of 9.3 , covering the compressed gas temperature range of $650-900 \mathrm{~K}$ and varying compressed gas pressures. In addition, many combustion products were identified in their work including bicyclic epoxides, cyclic ketones, unsaturated aliphatic aldehydes and conjugated alkenes. Stoichiometric mixtures of fuel and 'air' were used, with the diluent consisting of various mixtures of $\mathrm{N}_{2} / \mathrm{Ar} / \mathrm{CO}_{2}$ enabling the heat capacity of the mixture to be varied, and thus the compressed gas temperature. The pressure at top dead centre (TDC) was varied between 6.9 and $13.8 \mathrm{~atm}$, this being dependent on the initial gas pressure used as well as the combination of the inerts making up the diluent gas composition. We have simulated their experimental results assuming a homogeneous reactor, using $\mathrm{SENKIN}^{43}$ and $\mathrm{AURORA}^{44}$ codes in the Chemkin suite of codes. The temperature and species concentrations were assumed to be uniform across the combustion chamber. In the first series of calculations constant volume adiabatic calculations are performed at the conditions at the end of compression. As will be seen 
later, these calculations are quite accurate. The effect of including the compression stroke is small and the effect of heat loss is important only for the lowest temperatures.

Lemaire et al. report their experimental data for a range of compressed gas pressures, 7-9 atm and 11-14 atm, and we have assumed an average pressure of 8 atm and 12.5 atm for our simulations, a diluent composition of $\mathrm{N}_{2}$ only and compressed temperatures within the range of $650-900 \mathrm{~K}$ as the initial conditions for constant volume calculations. The effect of including the actual diluent composition on the computed ignition delay time is very small since the compressed gas temperature is specified. The ignition delay time in the model calculations is defined as the time from the end of compression to the maximum rate of pressure rise due to ignition. The results shown in Figures 6 and 7 illustrate the model predicted ignition delay times for the adiabatic, constant volume calculations versus the RCM experimental data of Lemaire et al. ${ }^{11}$

The model predicted total ignition delay times, as well as the cool flame measurements are shown to be within reasonable agreement of these experimental data. The trend of decreasing ignition delay times with increasing pressure agrees well between the experiments and the model for the entire temperature range in question. Note that the scale for ignition delay time is reduced at the higher pressure used in Figure 7. Prominent NTC behavior was observed for both pressure studies conducted. The model reproduced two stage ignition for both pressures investigated, and up to compressed gas temperatures of $\sim 770 \mathrm{~K}$. Figure 8 illustrates the model predicted cool flame and total ignition delay times, as well as depicting the transition into the NTC region where the ignition delay times are seen to elongate. The two stage ignition, or cool flame, is observed as a small 'shoulder' in the pressure-time profile. The experimental data shows that 
two stage ignition was recorded up to temperatures of approximately $800 \mathrm{~K}$ (see temperature when open symbol terminates in Figures 6 and 7), however, two stage ignition was not observed in the simulations at temperatures greater than $770 \mathrm{~K}$ (see temperature when dotted line terminates in Figures 6 and 7).

Results from a simulation were compared to the experimental results at $727 \mathrm{~K}$ and 7.4 atm, where experimental species measurements were made for various bicyclic epoxides, cyclic ketones, unsaturated aliphatic aldehydes and conjugated alkenes. In these experiments, selected reactive mixtures were allowed to expand into a sampling vessel and were analyzed qualitatively by gas chromatography and mass spectrometry, as well as quantitative intermediate product determination. Figures 9 through 14 illustrate the model prediction of various species that were measured experimentally in the RCM. The measured and predicted fuel concentration history is shown in Figure 9. Results are shown as percent carbon in the fuel since this is the quantity measured in the experiments. The model seems to indicate more fuel is consumed in the first stage ignition than that consumed in the experiments. For the intermediate species, the model predicts most of the species recorded experimentally very well. Results for intermediate species are shown versus percent fuel consumed so that differences in the fuel concentration history are removed from the comparison. Our model predicts the formation of cyclohexa-1,3-diene and benzene products from the dehydrogenation reaction path of cyclohexane, in agreement with the observations of some cyclohexane studies ${ }^{4,5,11,12,26}$. However, benzene is under predicted when compared to the experimentally measured quantity. Reaction flux analysis has shown that most of the benzene produced in the simulation comes from the series of dehydrogenation reactions of cyclohexane, leading to benzene via cyclohexene and cyclohex-1,3-diene. In addition, our model under predicts the amount of 1,2-epoxycyclohexane. Reaction flux analysis showed that the 
direct elimination pathway of $\mathrm{RO}_{2}$ forming olefin $+\mathrm{HO}_{2}$ and reduced the amount of $\mathrm{RO}_{2}$ available to isomerize to $\mathrm{QOOH}$ (chx1q2j) and form 1,2-epoxycyclohexane (chxyo12), as depicted in Figure 3.

\section{Some observations using the 'Alternative' $\mathrm{O}_{2} \mathrm{QOOH}$ reaction class}

As we describe in Chemical Kinetic Model section of this paper, we include this reaction class in our work on cyclohexane. In the previous studies on $n$-heptane and iso-octane by Curran et al. ${ }^{27,28}$, only internal $\mathrm{H}$-atom isomerisation steps for $\mathrm{O}_{2} \mathrm{QOOH}$ are considered, such that the products were always a stable carbonyl-hydroperoxide species and a hydroxyl radical, Figure 4. This choice was based on analysis of reaction paths ad $\mathrm{C}-\mathrm{H}$ bond strength arguments. However, consideration of ring-strain energies dictate that in many instances other conventional hydrogen atoms, which may form 5-, 6- or 7- membered transitions states, are also available. Thus, $\mathrm{O}_{2} \mathrm{QOOH}$ can also isomerize to form what we term 'alternative' $\mathrm{O}_{2} \mathrm{QOOH}$, which can then ultimately decompose to a different set of products. A recent study by this author completed the addition of such 'alternative' $\mathrm{O}_{2} \mathrm{QOOH}$ species and reactions to the $n$-heptane mechanism of Curran et al. ${ }^{27,28}$. Silke et al. ${ }^{45,46}$ found that for some experimental parameters, the addition of this reaction class improved the performance of the $n$-heptane mechanism; however, for other experimental parameters the $n$-heptane model deteriorated in its ability to match the experiments. Moreover, the recommendation was that this reaction class should be included.

Table 3 documents the rate constants that were used for the 'alternative' $\mathrm{O}_{2} \mathrm{QOOH}$ reaction class. During the course of this work, we found it necessary to reduce the activation energy used by $3 \mathrm{kcal} \mathrm{mol}^{-1}$ in order to obtain agreement with the experiments. Figure 15 illustrates a 
comparison of the simulations a) where the activation energy was estimated based on the reaction rate rules for analogous non-cyclic alkylperoxy isomerisations, the definition for which is listed in Table 2 for 6 and 7 membered rings, and b) where these activation energies described for a) are reduced by $3 \mathrm{kcal} \mathrm{mol}^{-1}$.

Sun and Bozzelli ${ }^{47}$ recently performed $a b$ initio and density functional calculations to evaluate reaction paths and kinetics for neo-pentyl oxidation. In their study, they report an activation energy of approximately $23.8 \mathrm{kcal} \mathrm{mol}^{-1}$ for the $\mathrm{RO}_{2}$ to $\mathrm{QOOH}$ isomerisation. The subsequent second isomerisation reactions, namely $\mathrm{O}_{2} \mathrm{QOOH}$ forming carbonylhydroperoxide or 'alternative' $\mathrm{O}_{2} \mathrm{QOOH}$ have slightly lower activation energies, of $22.4 \mathrm{kcal} \mathrm{mol}^{-1}$ and $22.6 \mathrm{kcal}$ $\mathrm{mol}^{-1}$ respectively. We highlight the Bozzelli work, as an interesting analogy to our own reaction rates - when we reduced the barrier of the 'alternative' $\mathrm{O}_{2} \mathrm{QOOH}$ by $3 \mathrm{kcal} \mathrm{mol}^{-1}$, we were using a value similar to energy barrier for carbonylhydroperoxide formation, this being same trend of activation energies in use for $\mathrm{O}_{2} \mathrm{QOOH}$ in the Sun and Bozzelli study.

Sensitivity analysis was carried for both versions of the mechanism, firstly where the activation energy of the alternative $\mathrm{O}_{2} \mathrm{QOOH}$ isomerisation was based on analogous cyclic alkylperoxy isomerisations (Figure 16) and secondly where this activation energy has been reduced by $3 \mathrm{kcal}$ $\mathrm{mol}^{-1}$ (Figure. 17).

The sensitivity analysis in Figure 16 shows that $\mathrm{O}_{2} \mathrm{QOOH}$ proceeding via the carbonylhydroperoxide channel (labeled $\mathrm{O} 2 \mathrm{QOOH}=\mathrm{Keto}+\mathrm{OH})$ contributes to the acceleration of the oxidation process. Indeed, isomerisation to 'alternative' $\mathrm{O}_{2} \mathrm{QOOH}$ contributes to much the same extent (labeled $\mathrm{O} 2 \mathrm{QOOH}=$ altern. $\mathrm{O}_{2} \mathrm{QOOH}$ ). What is remarkable is loss of a second $\mathrm{OH}$ 
from the carbonylhydroperoxide (labeled Keto $=$ Product $+\mathrm{OH}$ ), is accelerating in comparison to the decomposition of products formed via the 'alternative' $\mathrm{O}_{2} \mathrm{QOOH}$ isomerisation (labeled $\mathrm{O}_{2} \mathrm{QOOH}$ altern. $=$ Product $\left.+\mathrm{OH}\right)$, which is actually retarding at $650 \mathrm{~K}$.

In Figure 17 the sensitivity analysis where both $\mathrm{O}_{2} \mathrm{QOOH}$ isomerisation paths have the same activation energies, the formation of carbonylhydroperoxide accelerates the oxidation process in comparison to the formation of 'alternative' $\mathrm{O}_{2} \mathrm{QOOH}$, which actually retards the oxidation process at 650 and $727 \mathrm{~K}$. Notably, the 'alterative' pathway accelerates the oxidation process (labeled $\mathrm{O}_{2} \mathrm{QOOH}$ altern. $=$ Product $+\mathrm{OH}$ ) more than loss of an $\mathrm{OH}$ from the carbonylhydroperoxide (labeled Keto $=$ Product $+\mathrm{OH})$.

This leads us to conclude that when similar activation barriers are used for both isomerisation routes, although the $\mathrm{O}_{2} \mathrm{QOOH}$ isomerisation to carbonylhydroperoxide is favorable or at least comparable to the 'alternative' isomerisation path, the products formed via the 'alternative' $\mathrm{O}_{2} \mathrm{QOOH}$ isomerisation route decompose more readily to $\mathrm{OH}$, and contribute to the increased reactivity observed in our mechanism, especially at higher temperatures. The fact that this feature is notable at higher temperatures, such as $800 \mathrm{~K}$, conforms to the fact that the activation energy barriers associated with certain reactions are more easily over come at higher temperatures.

Finally, we performed an identical simulation to that conducted for Figure 6, and as before we assumed a homogeneous adiabatic reactor at TDC, and used SENKIN $^{43}$ constant volume simulations. For this simulation, we developed a version of our current (more reactive) mechanism that had all of these 'alternative' $\mathrm{O}_{2} \mathrm{QOOH}$ species and reactions removed, in order to investigate the effect of not considering $\mathrm{O}_{2} \mathrm{QOOH}$ 'alternative' reaction class at all. As in 
Figure 6, we used an average pressure of 8 atm, a diluent composition of $\mathrm{N}_{2}$ only and compressed temperatures within the range of 650-900 K, as the initial conditions for the constant volume calculations. The results of the model predicted ignition delay times, excluding the 'alternative' $\mathrm{O}_{2} \mathrm{QOOH}$ reaction class are compared to our simulation where such 'alternatives' are included in the mechanism (at the same activation barrier as the $\mathrm{O}_{2} \mathrm{QOOH}$ isomerisation to carbonylhydroperoxide) and are depicted in Figure 18.

Figure 18 shows in the low temperature region of $\sim 665 \mathrm{~K}$ the ignition delay time predicted was comparable to the experimentally recorded time. However, from $725-800 \mathrm{~K}$, a large decrease in reactivity is seen for the version of the mechanism where the 'alternative' $\mathrm{O}_{2} \mathrm{QOOH}$ reaction class is excluded. The reactivity of the mechanism deteriorates dramatically such that peak of the NTC region is at $\sim 190 \mathrm{~ms}$ in comparison to $\sim 90 \mathrm{~ms}$ for the mechanism where the 'alternative' $\mathrm{O}_{2} \mathrm{QOOH}$ are included. In addition, the peak of the NTC is slightly off set, occurring at $\sim 800 \mathrm{~K}$ in comparison to the slightly higher temperature of $\sim 820 \mathrm{~K}$ for the model where the 'alternative' $\mathrm{O}_{2} \mathrm{QOOH}$ are included and the experimental data. We conclude from these calculations, the high sensitivity observed in relation to the 'alternative' $\mathrm{O}_{2} \mathrm{QOOH}$ pathways, that the inclusion of such 'alternative' $\mathrm{O}_{2} \mathrm{QOOH}$ isomerisations, forming new $\mathrm{O}_{2} \mathrm{QOOH}$ rather than the conventional isomerisation route to carbonyl-hydroperoxide and hydroxyl radical, when the activation energy used is comparable to the reactions of $\mathrm{O}_{2} \mathrm{QOOH}$ forming carbonylhydroperoxide, the 'alternatives' are important for accurate prediction of ignition delay times for cyclohexane, and account for much of the reactivity of the system in the temperature range $700-850 \mathrm{~K}$. 


\section{Inclusion of Heat Loss}

In rapid compression machine experiments, the issue of heat loss to the combustion chamber as well as reaction occurring during the compression stroke is frequently discussed ${ }^{27,48-50}$. Indeed, heat loss is commonly neglected in simulations and very often there are reactions that can occur in the final portion of the compression stroke, which are likely to contribute to fuel consumption, especially when ignition delay times are significantly short, such as those observed with $n$ heptane in rapid compression machine studies ${ }^{48,51}$. Lemaire et al. ${ }^{11}$ report that for the Lille RCM cyclohexane studies, reaction during the compression stroke was never detected under their experimental conditions, since no trace of oxidation products were recorded at TDC.

We have developed a heat loss profile for the Lille rapid compression machine, in an effort to better characterize our reactive simulations of oxidation in this machine. The effect of heat loss to combustion chamber walls was estimated by matching experimental and computed pressure histories for non-reactive gas mixtures. The volume history for the compression stroke was based on a displacement history provided by the Lille group ${ }^{52}$. The displacement history was slightly modified to achieve the experimentally measured pressure at the end of compression. After the end of compression, the volume was expanded to simulate the effect of heat loss which reduces the pressure and thereby the temperature in the chamber. The adiabatic core gases that control autoignition are mainly affected by heat loss in this manner. This approach follows that of Tanaka et al. $^{53}$ and Mittal et al. ${ }^{54}$. The resulting computed pressure history incorporating the compression stroke and post-compression period is shown in Figure 19, and is compared to the experimentally measured pressure-history. 
An experimentally measured pressure history for a non reactive mixture (where $\mathrm{O}_{2}$ is replaced by $\mathrm{N}_{2}$ ) corresponding to the reactive mixture compositions in Table 4 were provided by the Lille RCM group and these were used to establish the accuracy of the volume history generated.

In addition, we tested our accuracy in prediction of the compressed gas pressure using the reactive experimental mixture compositions in Table 4, where the $\mathrm{O}_{2}$ component included, but using a mechanism where all the reaction rate constants are set to zero. The comparison of the experimental compressed gas temperature and the simulated compressed gas temperature are illustrated in Figure 20.

In a series of calculations, we examined the effect of including different degrees of fidelity in the compression and heat transfer model. We compared three cases at a compressed a temperature of approximately $737 \mathrm{~K}$ :

1) a constant volume calculation with no heat loss

2) the post compression period only with heat loss

3) the full compression stroke and post compression period with heat loss included throughout.

Mixture composition 4 (Table 4) was used and the results of the different calculations are tabulated below in Table 5:

The largest change in the results is seen from case 1, where heat loss after compression was neglected, to case 2 where the heat loss is included, Table 5 . Very little difference was noted between case 2 where the compression stroke was not considered and case 3 where the full compression stroke was included. This reinforces the conclusion of Lemaire et al. that reaction 
during the stroke was not a consideration at this compressed gas temperature, for cyclohexane experiments in the Lille $\mathrm{RCM}^{11}$.

The reactive model with our heat loss profile was used to simulate the experiments of Lemaire et al., beginning at the start of the compression stroke. The inclusion of the heat loss profile in our simulations led to an increase of approximately a factor of 7 in computer time. The initial mixture compositions are defined in Table 4 and the initial temperature and pressure for each was $354 \mathrm{~K}$ and 350 torr respectively. Figure 21 shows the effect of including heat loss on the ignition delay times predicted.

The addition of the heat loss profile elongates the predicted ignition delay time in the temperature range of $650-700 \mathrm{~K}$, when compared to the adiabatic simulation illustrated in Figure 6. As temperatures of $725 \mathrm{~K}$ and greater are reached and the NTC region is encountered, the model prediction with heat loss actually simulates the experimental data slightly better than the adiabatic calculation. Moreover, at higher temperatures $860-870 \mathrm{~K}$, the ignition delay times are marginally faster than the adiabatic calculation. This is due to reaction during the compression stroke, occurring in this higher temperature region.

\section{Jet stirred reactor experiments}

Voisin et al. ${ }^{12}$ and El Bakali et al. $^{13}$ reported experimental results on the oxidation of cyclohexane in a jet-stirred reactor incorporating the low and high temperature regimes (750$1,150 \mathrm{~K}$ ), with equivalence ratios $0.5 \leq \varphi \leq 1.5,99 \%$ dilution by nitrogen, and at pressures of 1 , 2, 5 and $10 \mathrm{~atm}$. The residence time varied from $0.07 \mathrm{sec}$ for $1 \mathrm{~atm}, 0.1 \mathrm{sec}$ for $2 \mathrm{~atm}, 0.25 \mathrm{sec}$ 
for $5 \mathrm{~atm}$ and $0.5 \mathrm{sec}$ for $10 \mathrm{~atm}$ studies. Low temperature chemistry characteristics, such as two stage ignition, were not observed experimentally. Under the very dilute conditions of these experiments, the concentration of fuel radical and $\mathrm{O}_{2}$ are very low so that little cyclohexylperoxy $\left(\mathrm{RO}_{2}\right)$ radical is formed that is needed for low temperature chemistry.

Simulations were performed under isothermal, constant pressure conditions and assumed perfect mixing of the reactants. Reactant concentrations, intermediate and final concentrations were obtained and are compared to the experimental results in Figures 22 through 26 . We first present the results at the lowest pressure considered ( $2 \mathrm{~atm})$, for stoichiometric mixtures of $0.15 \%$ cyclohexane, Figure 22 .

Overall, species concentrations are reproduced satisfactorily. Figure 22(a) shows the profiles for the fuel, oxygen, carbon monoxide and carbon dioxide, as well as hydrogen and formaldehyde. The predicted profile for fuel consumption is somewhat faster than that obtained experimentally above $900 \mathrm{~K}$, and thus the subsequent prediction of the formation of various species are less accurate and deviate from the experimental profiles, Figure 22(b) and (c). Note that the experimental fuel profile shows an extended flat region from $850-1,050 \mathrm{~K}$. The end of this extended flat region is the minimum temperature for reaction. The extended flat region is shortened at $10 \mathrm{~atm}$ as seen in Figures 24, 25 and 26. At higher pressures, it is possible for the fuel mixture to react at lower temperature.

In the next series of results, the pressure is increased to $5 \mathrm{~atm}$ and the mixture is stoichiometric with $0.15 \%$ cyclohexane, Figure 23 . The predicted species concentrations at this pressure are considerably better than those predicted at 2 atm, with the experimental profiles being produced 
quite well. Figure 23(a) shows the profiles for the fuel, oxygen, carbon monoxide and carbon dioxide, as well as hydrogen and formaldehyde, and all profiles are predicted well by the model. Figure 23(b) depicts methane, ethylene and 1,3-butadiene amongst other species. These are quite well predicted, although ethylene is somewhat under predicted, especially at $960 \mathrm{~K}$, where it peaks in the experimentally recorded profile. The reactions forming ethylene will be discussed later. Figure 23(c) illustrates that cyclohexene is well predicted, although the model peaks at the slightly lower temperature of $850 \mathrm{~K}$ in contrast to the experimental peak at $\sim 875 \mathrm{~K}$. Other species, including cyclohexa-1,3-diene and benzene are over predicted by the model.

Figure 24 shows comparison between computed and experimental results for stoichiometric mixtures at the highest pressure considered (10 atm), with $0.1 \%$ cyclohexane and at a residence time of $0.5 \mathrm{sec}$. The model performs well in predicting fuel consumption, oxygen depletion, as well as the formation of hydrogen, carbon monoxide, carbon dioxide and formaldehyde, Figure 24(a). In Figure 24(b), the production of methane and cyclohexene are particularly well captured. The model predicts less ethylene than observed in the experiments of Voisin et al. ${ }^{12}$, especially at temperatures when the fuel has mostly been consumed. This discrepancy will be discussed later. In addition, benzene is over predicted, as are 1,3-butadiene and cyclohexa-1,3-diene in Figure 24(c).

Agreement was acceptable for most of the simulations. The effect of pressure on our model predictions is depicted in Figures 22-24, and we find that at a lower pressure of 2 atm our simulation is less accurate overall than our simulation at higher pressure of $10 \mathrm{~atm}$. It may be that our model is not getting the pressure dependence right and this warrants more attention and investigation. 
In the earlier jet stirred reactor work of Voisin et al. ${ }^{12}$ they reported experimental data for cyclohexane at HCCI-like conditions of $\varphi=0.5$ and at $10 \mathrm{~atm}$. Figure 25 shows comparison between computed and experimental results for these conditions. Overall, species concentrations are produced very well, Figure 25(a)-(c). Most notably our model is still ineffective at predicting ethylene in jet stirred reactor environments. In addition, the model continues to over predict cyclohexa-1,3-diene and benzene.

The experimental measurements for these conditions are notable at temperatures greater than 750 K. An interesting feature is that our model predicts an NTC type behavior in the temperature range of 700-800 K for ethylene, Figure 25(b), 1,3-butadiene, cyclohexene, cyclohex-1,3-diene and benzene, Figure 25 (c). This feature was not captured in the experiments where data is recorded at temperatures of $\sim 750 \mathrm{~K}$ and greater, and temperatures below $750 \mathrm{~K}$ were not reported.

In addition, Voisin et al. reported experimental data for cyclohexane at fuel-rich, Diesel-like conditions of $\varphi=1.5$ and at $10 \mathrm{~atm}^{12}$. The model predicts a number of the species concentrations quite well, Figure 26(a)-(c). The shape of the fuel profile is well captured by the model.

Ethylene continues to be under predicted - a feature that this mechanism has repeatedly shown. At the lower pressures of 2 and 5 atm that were simulated, the model predicted amount of ethylene was acceptable. However, at a pressure of 10 atm the model faired less well in matching the experimental quantities of ethylene. Rate of production analysis was carried out at approximately $900 \mathrm{~K}$ for each of the jet stirred reactor conditions simulated in this work. 
Interestingly, for each of the conditions, $80 \%$ of the production of ethylene was from the same three reactions:

1. $\mathrm{C}_{2} \mathrm{H}_{5}+\mathrm{O}_{2}=\mathrm{C}_{2} \mathrm{H}_{4}+\mathrm{HO}_{2}$

2. $\mathrm{C}_{2} \mathrm{H}_{4}+\mathrm{C}_{4} \mathrm{H}_{7} 1-4=\mathrm{C}_{6} \mathrm{H}_{11}-16$

3. $\mathrm{C}_{4} \mathrm{H}_{7} 1-4=\mathrm{C}_{2} \mathrm{H}_{4}+\mathrm{C}_{2} \mathrm{H}_{3}$

In reaction step 2 above, $\mathrm{C}_{6} \mathrm{H}_{11}-16$ is the olefinic radical produced from the ring opening step of the fuel molecule. Figure 2 in the Chemical Kinetic Mechanism section of this paper illustrates the formation of $\mathrm{C}_{6} \mathrm{H}_{11}-16$. The problem of simulating $\mathrm{C}_{2} \mathrm{H}_{4}$ concentrations needs further investigation.

Variation in oxygen concentration at constant pressure of $10 \mathrm{~atm}$ was found to change the overall reactivity of the system. Under high oxygen concentration conditions $\left(1.8 \% \mathrm{O}_{2}\right)$, Figure 25(a)-(c), the fuel was oxidised at lower temperatures relative to stoichiometric conditions depicted in Figure 24(a)-(c). Under low oxygen conditions $\left(0.6 \% \mathrm{O}_{2}\right)$, Figure 26(a)-(c), oxidation occurred at higher temperatures relative to the stoichiometric experiments and simulations.

CONCLUSIONS The present study has developed a detailed reaction mechanism for the oxidation of cyclohexane. The mechanism has been used to simulate cyclohexane oxidation in a both rapid compression machine and a jet stirred reactor, incorporating the temperature range $650-1,150 \mathrm{~K}$, a range of pressures and various equivalence ratios. The overall reactivity of cyclohexane oxidation is well reproduced by the model, particularly for rapid compression machine experiments. In addition, many of the experimentally quantified intermediate species profiles from rapid compression machine studies are well reproduced by the model. This would indicate that most of the chemical pathways leading to their formation are well understood. Some 
attention is required in improving the model simulations of the stirred reactor experiments. The model was not able to reproduce the experimentally observed amount of 1,2-epoxycyclohexane. This result indicates a potential problem in the current understanding of the $\mathrm{R}+\mathrm{O}_{2}$ reaction system. When the direct elimination of $\mathrm{HO}_{2}$ from $\mathrm{RO}_{2}$ is included, the formation of 1,2epoxycyclohexane is unfavorable.

This mechanism was based on our previous modeling of hydrocarbon oxidation, in particular that of methylcyclohexane, as we attempted to confirm and extend the conclusions of that work, in relation to specific rules for cyclo-systems. In addition, our goal was to develop a unified approach to cycloalkanes such that similarities and differences in the correction terms between cyclic and acyclic isomerisation reactions were determined. In this paper we establish a methodology for addressing cyclic hydrocarbon species that may be used in for future mechanism development of other cyclic species.

An important feature of this mechanism is its ability to predict the formation of benzene via the dehydrogenation of cyclohexane. Benzene prediction under jet stirred reactor conditions was quite good; however, improvement is needed in the model predicted benzene in rapid compression machine environments. Depending on experimental conditions, the literature reports the dehydrogenation of cyclohexane to produce benzene as the dominant pathway leading to soot formation, or routes that require aromatic ring formation by reactions involving $\mathrm{C}_{3} \mathrm{H}_{3}, \mathrm{C}_{4} \mathrm{H}_{5}$ and similar smaller species. Under the conditions of the present study, we observe benzene formation from the dehydrogenation pathway. 
ACKNOWLEDGMENT This work was supported by the U.S. Department of Energy, Office of Freedom CAR and Vehicle Technologies, and the authors thank program managers Kevin Stork and Gurpreet Singh for their support of this work. This work was carried out under the auspices of the U.S. Department of Energy by University of California Lawrence Livermore National Laboratory under Contract No. W-7405-Eng-48. E.J. Silke thanks Dr. Abderrahman El Bakali for insight and discussion on the jet stirred reactor experiments and simulations.

SUPPORTING INFORMATION DESCRIPTION This newly developed cyclohexane mechanism is available from the author, by emailing silke2@1lnl.gov

\section{REFERENCES}

\section{1. http://www.rense.com/general37/petrol.htm}

2. Northrop Grumman 'Diesel Fuel Oils, 2003', Report NGMS-232 PPS January (2004).

3. J. Guthrie, P. Fowler, and R. Sabourin, 'Gasoline and Diesel Fuel Survey' (2003). Available at http://www.ec.gc.ca/cleanairairpur/CAOL/OGEB/fuels/reports/fullreport/pdf/FullReport2003_e.pdf

4. M. E. Law, P.R. Westmoreland, T. A. Cool, J. Wang, N. Hansen, C. A. Taatjes, T. Kasper, Proc Combust. Inst. 31 (2007).

5. S.K. Gulati and R.W. Walker, J. Chem. Soc. Faraday Trans. 85: 1799-1812 (1989).

6. S.M. Handford-Styring and R.W. Walker, Phys. Chem. Chem. Phys. 3: 2043-2052 (2001).

7. C.K. Westbrook, Proc Combust. Inst. 28: 1563-1577 (2000). 
8. J.M. Simmie, Prog. in Energy Combust. Sci. 29: 599-634 (2003).

9. B. Sirjean, F. Buda, H. Hakka, P.A. Glaude, R. Fournet, V. Warth, F. Battin-Leclerc, Proc Combust. Inst. 31 (2007).

10. G. Dayma, P.A. Glaude, R. Fournet, F. Battin-Leclerc, Int. J. Chem. Kin. 35: 273-285 (2003).

11. O. Lemaire, M. Ribaucour, M. Carlier, R. Minetti, Combust. Flame 127: 1971-1980 (2001).

12. D. Voisin, A. Marchal, M. Reuillon, J.C. Boettner, M. Cathonnet, Combust. Sci. Tech. 138: 137-158 (1998).

13. A. El Bakali, M. Braun-Unkhoff, P. Dagaut, P. Frank, M. Cathonnet, Proc. Combust. Inst. 28: $1631-1638(2000)$.

14. F. Billaud, P. Chaverot, M. Berthelin, E. Freund, Ind. Eng. Chem. Res. 27: 759-764 (1988).

15. B.H. Bonner and C.F.H. Tipper, Combust. Flame 9: 317-327 (1965).

16. A.P. Zeelenberg and H.W. de Bruijn, Combust. Flame 9: 281-295 (1965).

17. T.J. Snee and J.F. Griffiths, Combust. Flame 75: 381-395 (1989).

18. S.E. Klaï and F. Baronnet, J. Chim. Phys. 90: 1929-1950 (1993).

19. S.E. Klaï and F. Baronnet, J. Chim. Phys. 90: 1951-1998 (1993).

20. C. S. McEnally and L. D. Pfefferle, Combust. Flame 136: 155-167 (2004).

21. S.G. Davis and C.K. Law, Combust. Sci. Tech. 140: 427-449 (1998). 
22. F. Buda, B. Heyberger, R. Fournet, P.A. Glaude, V. Warth, F. Battin-Leclerc, Energy \& Fuels 20: 1450-1459 (2006).

23. C. Cavallotti, R. Rota, T. Faravelli, E. Ranzi, Proc Combust. Inst. 31, in press (2007).

24. S. Granata, T. Faravelli, E. Ranzi, Combust. Flame 132: 533-544 (2003).

25. J.A. Miller, M.J. Pilling and J. Troe, Proc Combust. Inst. 30: 43-88 (2005).

26. P. J. Bennett, D. Gregory, R. A. Jackson, Combust. Sci. Tech. 115: 83-103 (1996).

27. H.J. Curran, P. Gaffuri, W.J. Pitz, C.K. Westbrook, Combust. Flame 114: 149-177 (1998).

28. H.J. Curran, P. Gaffuri, W.J. Pitz, C.K. Westbrook, Combust. Flame 129: 253-280 (2002).

29. W.J. Pitz, C.V. Naik, T. Ní Mhaoldúin, C.K. Westbrook, H.J. Curran, J.P. Orme, J.M. Simmie, Proc Combust. Inst. 31, in press (2007).

30. W.J. Pitz, R. Seiser, J.W. Bozzelli, K. Seshadri, C.J. Chen, I.D. Costa, R. Fournet, F. Billaud, F. Battin-Leclerc, C.K. Westbrook, Chemical Kinetic Study of Toluene Oxidation under Premixed and Non-premixed Conditions, Lawrence Livermore National Laboratory, UCRLCONF-201575 (2003).

31. E.R. Ritter and J. W. Bozzelli, Int. J. Chem. Kinet. 23: $767-778$ (1991).

32. T.H. Lay, J.W. Bozzelli, A.M. Dean, E.R. Ritter, J. Phys. Chem. 99: 14514-14527 (1995).

33. S.W. Benson, Thermochemical Kinetics, John Wiley and Sons Inc., New York (1976).

34. J.P. Orme, H.J. Curran, J.M. Simmie, J. Phys. Chem. A 110: 114-131 (2006).

35. W. Tsang, Int. J. Chem. Kin. Vol. X: 1119-1138 (1978). 
36. M. Scott and R.W. Walker, Combust. Flame 129: 365-377 (2002).

37. H.J. Curran, Int. J. Chem. Kin. 38: 250-275 (2006).

38. D.M. Matheu, W.H. Green, J.M. Grenda, Int. J. Chem. Kin. 35: 95-119 (2003).

39. R.W. Walker and C. Morley, in Comprehensive Chemical Kinetics, Vol. 35, page 1 (R.G. Compton and G. Hancock, Eds.), Elsevier, New York (1997).

40. J.D. DeSain, S.J. Klippenstein, J.A. Miller, C.A. Taatjes, J. Phys. Chem. A 107 : 4415-4427 (2003).

41. H. Carstensen, C.V. Naik and A.M. Dean, J. Phys. Chem. A 109 : 2264-2281 (2005).

42. W. Tsang and R.F. Hampson, J. Phys. Chem. Ref. Data 15: (1986).

43. R.J. Kee, F.M. Rupley, J.A. Miller, M.E. Coltrin, J.F. Grcar, E. Meeks, H.K. Moffat, A.E. Lutz, G. Dixon-Lewis, M.D. Smooke, J. Warnatz, G.H. Evans, R.S. Larson, R.E. Mitchell, L.R. Petzold, W.C. Reynolds, M. Caracotsios, W.E. Stewart, P. Glarborg, C. Wang, O. Adigun, W.G. Houf, C.P. Chou, S.F. Miller, Chemkin Collection, v3.31 Reaction Design Inc., San Diego, CA (2001).

44. R. J. Kee, F.M. Rupley, J.A. Miller, M.E. Coltrin, J.F. Grcar, E. Meeks, H.K. Moffat, A.E. Lutz, G. Dixon-Lewis, M.D. Smooke, J. Warnatz, G.H. Evans, R.S. Larson, R.E. Mitchell, L.R. Petzold, W.C. Reynolds, M. Caracotsios, W.E. Stewart, P. Glarborg, C. Wang, O. Adigun, W.G. Houf,

C.P. Chou, S.F. Miller, P. Ho, and D.J. Young, CHEMKIN Release 4.0.2, Reaction Design, Inc., San Diego, CA (2005). 
45. E.J. Silke, 'The Influence of Fuel Structure as Demonstrated by the Isomers of Heptane: a Rapid Compression Machine \& Detailed Kinetic Modeling of n-Heptane', Ph.D. Thesis, Chemistry Dept., National University of Ireland, Galway (2005).

46. E.J. Silke, H.J. Curran and J.M. Simmie "A Rapid Compression Machine Modelling Study of the Heptane Isomers" European Combustion Meeting (2005).

47. H. Sun and J.W. Bozzelli, J. Phys. Chem. A 108 : 1694-1711 (2004).

48. J.F. Griffiths, P.A. Halford-Maw and D.J. Rose, Combust. Flame 95: 291-306 (1993).

49. J.F. Griffiths, K.J. Hughes, M. Schreiber and C. Poppe, Combust. Flame 99: 533-540 (1994).

50. A. Cox, J.F. Griffiths, C. Mohammed, H.J. Curran, W.J. Pitz and C.K. Westbrook, Proc. Combust. Inst. 26: 2685-2692 (1996).

51. E.J. Silke, H.J. Curran and J.M. Simmie, Proc Combust. Inst. 30: 2639-2647 (2005).

52. M. Ribaucour, private communication to E.J. Silke (Summer 2006).

53. S. Tanaka, F. Ayala and J.C. Keck, Combust. Flame 133: 467-81 (2003).

54. G. Mittal and C.-J. Sung, Combust. Flame 145: 160-180 (2006).

55. A. El Bakali, private communication to E.J. Silke (Summer 2006). 


\section{TABLES}

\begin{tabular}{|c|c|c|c|c|}
\hline $\begin{array}{l}\text { Ring size in } \\
\text { transition state }\end{array}$ & $\mathbf{A}$ & $\mathbf{n}$ & $\mathbf{E a}$ & Rate at $750 \mathrm{~K}$ \\
\hline \multicolumn{5}{|c|}{ Curran et al. ${ }^{28}$ non-cyclic Alkylperoxy: } \\
\hline 5 & $1.0 \mathrm{e}+11$ & 0 & 26850 & $6.0 \mathrm{e}+3$ \\
\hline 6 & $1.25 \mathrm{e}+10$ & 0 & 20850 & $4.2 \mathrm{e}+4$ \\
\hline 7 & $1.56 \mathrm{e}+9$ & 0 & 19050 & $8.8 \mathrm{e}+3$ \\
\hline \multicolumn{5}{|c|}{ Handford-Styring and Walker ${ }^{6}$ Cyclohexylperoxy: } \\
\hline $5(1,4 s)$ & $8.71 \mathrm{e}+11$ & 0 & 32433.1 & $3.1 \mathrm{e}+2$ \\
\hline $6(1,5 s)$ & $6.46 \mathrm{e}+11$ & 0 & 29517.2 & $1.6 \mathrm{e}+3$ \\
\hline $7(1,6 s)$ & $7.59 \mathrm{e}+10$ & 0 & 26816.4 & $1.2 \mathrm{e}+3$ \\
\hline \multicolumn{5}{|c|}{ Walker and Morley ${ }^{39}$ non-cyclic Alkylperoxy: } \\
\hline 5 & $1.41 \mathrm{e}+12$ & 0 & 31787.8 & $7.7 \mathrm{e}+2$ \\
\hline 6 & $1.74 \mathrm{e}+11$ & 0 & 26290.6 & $3.8 \mathrm{e}+3$ \\
\hline \multirow[t]{2}{*}{7} & $2.19 \mathrm{e}+10$ & 0 & 21510.5 & $1.2 \mathrm{e}+4$ \\
\hline & $\begin{array}{c}\text { Walker: } \\
\text { Ratio of A factors } \\
\text { Cyclo/normal }\end{array}$ & & $\begin{array}{c}\text { Walker: } \\
\text { Difference in Ea } \\
\text { Cyclo-normal }\end{array}$ & $\begin{array}{c}\text { Walker: } \\
\text { k ratio } \\
\text { k cyclo/k normal }\end{array}$ \\
\hline 5 & 0.62 & & 645.3 & 0.4 \\
\hline 6 & 3.72 & & 3226.6 & 0.43 \\
\hline 7 & 3.47 & & 5305.9 & 0.1 \\
\hline \multicolumn{5}{|c|}{ Curran et al. Alkylperoxy rate modified for cyclic $\mathrm{RO}_{2}$ system - in use in this work } \\
\hline 5 & $4.94 \mathrm{e}+11^{\mathrm{a}}$ & 0 & $31000^{b}$ & $4.6 \mathrm{e}+2$ \\
\hline 6 & $1.86 \mathrm{e}+11^{\mathrm{c}}$ & 0 & $24076.6^{\mathrm{d}}$ & $1.8 \mathrm{e}+4$ \\
\hline
\end{tabular}




\begin{tabular}{|c|c|c|c|c|}
\hline 7 & $1.08 \mathrm{e}+10$ & 0 & 24355.9 & $8.6 \mathrm{e}+2$ \\
\hline \multicolumn{5}{|c|}{${ }^{\mathrm{a}} \mathrm{A}_{\text {Curran }} \mathrm{x}$ ratio ${ }_{\text {(cyclo/normal) }} \mathrm{x}$ degeneracy and $\mathrm{x} 2$ for experimental agreement } \\
\hline \multicolumn{5}{|c|}{${ }^{\mathrm{b}} \mathrm{Ea}=\mathrm{Ea}$ for $\mathrm{HO}_{2}$ elimination of DeSain et al. ${ }^{40}+2 \mathrm{kcal}$} \\
\hline \multicolumn{5}{|c|}{${ }^{\mathrm{c}} \mathrm{A}_{\text {Curran }} \mathrm{x}$ ratio ${ }_{\text {(cyclo/normal) }} \mathrm{x}$ degeneracy } \\
\hline${ }^{\mathrm{d}} \mathrm{Ea}_{\text {Curran }}+$ & ormal) & & & \\
\hline
\end{tabular}

Table 1. Rate constant expressions for cyclic alkylperoxy $\left(\mathrm{RO}_{2}\right)$ isomerisation used in present study. Rate adjustment is illustrated $\left(\mathrm{cm}^{3}-\mathrm{mol}-\mathrm{sec}-\mathrm{cal}\right.$ units; all secondary C-H sites, rate at 750 $\mathrm{K}$ accounts for degeneracy).

\begin{tabular}{|c|c|c|c|}
\hline \multirow{2}{*}{$\begin{array}{c}\text { Cyclic } \\
\text { ether }\end{array}$} & \multicolumn{3}{|c|}{ Rate expression } \\
\cline { 2 - 4 } ring size & $\mathbf{A}$ & $\mathbf{n}$ & Ea \\
\hline 3 & $5.8 \times 10^{12}$ & 0 & 13400 \\
\hline 4 & $1.4 \times 10^{12}$ & 0 & 20000 \\
\hline 5 & $8.6 \times 10^{12}$ & 0 & 18500 \\
\hline
\end{tabular}

Table 2. Rate constant expression in use for cyclic ether formation from QOOH radicals $\left(\mathrm{cm}^{3}\right.$ mol-sec-cal units). These rate data are based on the recommendations of Cavallotti et al. ${ }^{23}$ and are modified as described to obtain agreement with the experimental results.

\begin{tabular}{|c|c|c|c|c|c|}
\hline $\begin{array}{c}\text { Ring Size in } \\
\text { transition State }\end{array}$ & $\mathbf{A}$ & n & Ea & Rate at $750 \mathrm{~K}$ & \\
\hline \multicolumn{6}{|c|}{$\begin{array}{l}\text { Curran et al. Alkylperoxy rate modified for cyclic } \mathrm{O}_{2} \mathrm{QOOH} \text { to Carbonyl-hydroperoxide system }- \text { in use in this } \\
\text { work }\end{array}$} \\
\hline 5 & $6.17 \mathrm{e}+10$ & 0 & 24495.3 & $4.5 \mathrm{e}+3$ & \\
\hline 6 & $4.64 \mathrm{e}+10$ & 0 & 21076.6 & $3.3 \mathrm{e}+4$ & \\
\hline
\end{tabular}




\begin{tabular}{|c|c|c|c|c|c|}
\hline 7 & $5.41 \mathrm{e}+9$ & 0 & 21355.9 & $3.2 \mathrm{e}+3$ & \\
\hline \multicolumn{6}{|c|}{ 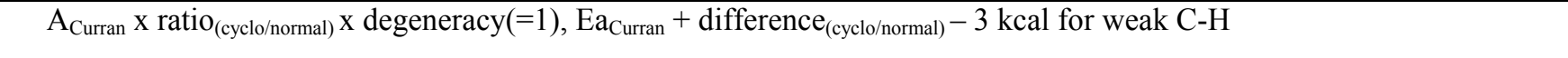 } \\
\hline \multicolumn{6}{|c|}{ Curran et al. Alkylperoxy rate modified for cyclic $\mathrm{O}_{2} \mathrm{QOOH}$ to 'alternative' $\mathrm{O}_{2} \mathrm{QOOH}$ system - in use in this work } \\
\hline 5 & $1.24 \mathrm{e}+11$ & 0 & 24495.3 & $1.2 \mathrm{e}+3$ & \\
\hline 6 & $1.86 \mathrm{e}+11$ & 0 & 21076.6 & $1.8 \mathrm{e}+4$ & \\
\hline 7 & $1.08 \mathrm{e}+10$ & 0 & 21355.9 & $8.6 \mathrm{e}+2$ & \\
\hline 5 & $2.48 \mathrm{e}+11$ & 0 & 24495.3 & $2.4 \mathrm{e}+3$ & \\
\hline 6 & $9.3 e+10$ & 0 & 21076.6 & $8.95 \mathrm{e}+3$ & \\
\hline 7 & $1.08 \mathrm{e}+10$ & 0 & 21355.9 & $8.6 \mathrm{e}+2$ & \\
\hline 5 & $2.48 \mathrm{e}+11$ & 0 & 24495.3 & $2.4 \mathrm{e}+3$ & $\bullet$ \\
\hline 6 & $1.86 \mathrm{e}+11$ & 0 & 21076.6 & $1.8 \mathrm{e}+4$ & \\
\hline $\begin{array}{l}A_{\text {Curran }} \mathrm{x} \\
\text { experiments }\end{array}$ & nal) $\mathrm{x} \operatorname{deg}$ & & Curran + & ence $_{\text {(cyclo/no }}$ & - $3 \mathrm{kcal}^{*}$ (*reduction for agreement wi \\
\hline
\end{tabular}

Table 3. Rate constant expressions for $\mathrm{O}_{2} \mathrm{QOOH}$ isomerisations used in present study. Rate adjustment is illustrated $\left(\mathrm{cm}^{3}-\right.$ mol-sec-cal units; all secondary $\mathrm{C}-\mathrm{H}$ sites, rate at $750 \mathrm{~K}$ accounts for degeneracy).

\begin{tabular}{|l|c|c|c|c|c|}
\hline Mixture & $\mathbf{C H X}$ & $\mathbf{O}_{\mathbf{2}}$ & $\mathbf{C O}_{\mathbf{2}}$ & $\mathbf{N}_{\mathbf{2}}$ & $\mathbf{A r}$ \\
\hline 1 & 0.0228 & 0.2053 & 0.1775 & 0.5944 & 0 \\
\hline 2 & 0.0228 & 0.2053 & 0.0772 & 0.6947 & 0 \\
\hline
\end{tabular}




\begin{tabular}{|l|l|l|l|l|l|}
\hline 3 & 0.0228 & 0.2053 & 0 & 0.7719 & 0 \\
\hline 4 & 0.0228 & 0.2053 & 0 & 0.6175 & 0.1544 \\
\hline 5 & 0.0228 & 0.2053 & 0 & 0.5403 & 0.2316 \\
\hline 6 & 0.0228 & 0.2053 & 0 & 0.386 & 0.3856 \\
\hline 7 & 0.0228 & 0.2053 & 0 & 0.2756 & 0.4963 \\
\hline 8 & 0.0228 & 0.2053 & 0 & 0.193 & 0.5789 \\
\hline 9 & 0.0228 & 0.2053 & 0 & 0.1158 & 0.6561 \\
\hline 10 & 0.0228 & 0.2053 & 0 & 0.054 & 0.7179 \\
\hline 11 & 0.0228 & 0.2053 & 0 & 0 & 0.7719 \\
\hline
\end{tabular}

Table 4. Mixture compositions used for volume history optimization ${ }^{52}$.

\begin{tabular}{|c|c|c|c|}
\hline Problem type & Tc / K & $\tau / \mathbf{m s}$ & $\begin{array}{l}\text { Cool } \\
\text { flame / ms }\end{array}$ \\
\hline 1. Adiabatic & 737 & 37 & 27 \\
\hline $\begin{array}{l}\text { 2. Post-comp. } \\
+\mathrm{Q}\end{array}$ & 737 & 41 & 33 \\
\hline $\begin{array}{l}\text { 3. Full stroke } \\
+\mathrm{Q}\end{array}$ & 735.5 & 40 & 32 \\
\hline
\end{tabular}

Table 5. The effect on simulated ignition delay time, depending on problem type in questions and whether a heat loss profile is included or not.

\section{FIGURE CAPTIONS}

Figure 1. The formation of benzene from cyclohexane, via cyclohexene and cyclohexa-1,3-diene.

Figure 2. An example of a ring opening reaction, followed by alkyl radical isomerisation. 
Figure 3. Potential energy diagram for the reaction of cyclohexyl radical (R) with $\mathrm{O}_{2}$, using thermodynamic properties determined in this work.

Figure 4. An example of the more conventional $\mathrm{O}_{2} \mathrm{QOOH}$ isomerisation leading to carbonylhydroperoxide $+\mathrm{OH}$.

Figure 5. An example of the type of 'alternative' $\mathrm{O}_{2} \mathrm{QOOH}$ isomerisations permitted in this work. Example shows 5-membered transition state and 2 possible routes of decomposition.

Figure 6. Experimental ${ }^{11}$ (points), pressure range 7-9 atm from a rapid compression machine investigation and model predicted ignition delay times (line) at $8 \mathrm{~atm}$. Open symbols and dashed lines correspond to cool flame ignition measurements.

Figure 7. Experimental ${ }^{11}$ (points), pressure range 11-14 atm from a rapid compression machine investigation and model predicted ignition delay times (line) at $12.5 \mathrm{~atm}$. Open symbols and dashed lines correspond to cool flame ignition measurements.

Figure 8. Model predicted pressure-time profiles for rapid compression machine experiments, depicting NTC behavior and the appearance and disappearance of cool flame phenomena. Curves correspond to the following end of compression temperatures: $1=690 \mathrm{~K}, 2=727 \mathrm{~K}, 3=$ $740 \mathrm{~K}, 4=770 \mathrm{~K}$ and $5=820 \mathrm{~K}$.

Figure 9. Comparison of cyclohexane consumption profile at $7.4 \mathrm{~atm}, \mathrm{~T}=727 \mathrm{~K}$ in the $\mathrm{RCM}$, experimental (points), model predicted (line). Time is the time after the end of compression.

Figure 10. Species profile of cyclohexene in RCM (navy blue, experimental (points), model (lines)) and hex5enal (red, experimental (points), model (lines)). 
Figure 11. Species profile of hex5enal in RCM (red, experimental (points), model (lines)), 1,2epoxycyclohexane (magenta, experimental (points), model (lines)), 1,3-epoxycyclohexane (green, experimental (points), model (lines)), and 1,4-epoxycyclohexane (blue, experimental (points), model (lines)).

Figure 12. Species profile of the soot precursors in RCM: cyclohexene (navy blue, experimental (points), model (lines)), cyclohexa-1,3-diene (blue, experimental (points), model (lines)) and benzene (green, experimental (points), model (lines)).

Figure 13. Species profile of 1,3-Butadiene in RCM (burgundy, experimental (points), model (lines)).

Figure 14. Species profile of ethene and ethyne (combined) in RCM (green, experimental (points), model (lines)).

Figure 15. Comparing the performance of the mechanism used in this work when Ea for 'alternative' $\mathrm{O}_{2} \mathrm{QOOH}$ reaction class is varied: Experimental (points), pressure range 7-9 atm and model predicted ignition delay times (lines) at 8 atm. A) Ea based on analogous cyclic alkylperoxy isomerisations, B) Ea as in A but with reduction of $3 \mathrm{kcal} \mathrm{mol}^{-1}$. Open symbols and dashed lines correspond to cool flame ignition measurements.

Figure 16. Sensitivity analysis for reactivity profile A in Figure 15, where Ea of 'alternative' $\mathrm{O}_{2} \mathrm{QOOH}$ paths is $3 \mathrm{kcal} \mathrm{mol}^{-1}$ higher than that for $\mathrm{O}_{2} \mathrm{QOOH}$ forming carbonylhydroperoxide. **Corresponds to negligible sensitivity.

Figure 17. Sensitivity analysis for reactivity profile B in Figure 15, where Ea of 'alternative' $\mathrm{O}_{2} \mathrm{QOOH}$ paths is the same as that for $\mathrm{O}_{2} \mathrm{QOOH}$ forming carbonylhydroperoxide. 
**Corresponds to negligible sensitivity at $800 \mathrm{~K}$ for two of the reaction classes considered in the sensitivity analysis.

Figure 18. Experimental (points), pressure range 7-9 atm and model predicted ignition delay times (lines) at $8 \mathrm{~atm}$. Red line is the version of the mechanism containing 'alternative' $\mathrm{O}_{2} \mathrm{QOOH}$ pathways, green line is that with these species and reactions completely removed from the mechanism. Open symbols and dashed lines correspond to cool flame ignition measurements.

Figure 19. Experiment pressure-time data ${ }^{52}$ from the RCM (dashed navy blue lines). Pressuretime profile obtained using volume history generated in this work (solid magenta line). Mixture conditions as defined for (4) in Table 4, using an unreactive mechanism (no reactions), pi $=350$ torr, $\mathrm{Ti}=351 \mathrm{~K}$, Experimental $\mathrm{Tc}=737 \mathrm{~K}$, Predicted $\mathrm{Tc}=736.5 \mathrm{~K}$.

Figure 20. Compressed gas temperature prediction using volume history profile generated in this work (solid symbol) versus experimental compressed gas temperature (open symbol). Mixture composition is according to Table 4. Model is using a mechanism where no reactions are allowed. For both model and experiment $\mathrm{Ti}=354 \mathrm{~K}$ and $\mathrm{pi}=350$ torr.

Figure 21. Experimental (points), pressure range 7-9 atm and model with heat loss predicted ignition delay times (lines). Open symbols and dashed lines correspond to cool flame ignition measurements.

Figure 22. $0.15 \%$ cyclohexane oxidation at $2 \mathrm{~atm}, \varphi=1.0, \tau=0.1 \mathrm{sec}$ in a jet stirred reactor. Experimental (points) ${ }^{13}$ and model predicted mole fraction for some of the species reported in the experimental study. Experimental and simulated fuel concentration times 5 for clarity. 
Figure 23. $0.15 \%$ cyclohexane oxidation at $5 \mathrm{~atm}, \varphi=1.0, \tau=0.25 \mathrm{sec}$ in a jet stirred reactor. Experimental (points) ${ }^{55}$ and model predicted mole fraction for some of the species recorded in the experimental study. Experimental and simulated fuel concentration times 5 for clarity.

Figure 24. $0.1 \%$ cyclohexane oxidation at 10 atm, $\varphi=1.0, \tau=0.5 \mathrm{sec}$ in a jet stirred reactor. Experimental (points) ${ }^{12,13}$ and model predicted mole fraction for some of the species reported in both experimental studies. Experimental and simulated fuel concentration times 5 for clarity.

Figure $25.0 .1 \%$ cyclohexane oxidation at $10 \mathrm{~atm}, \varphi=0.5, \tau=0.5 \mathrm{sec}$ in a jet stirred reactor. Experimental (points) ${ }^{12}$ and model predicted mole fraction for some of the species reported in the experimental studies. Experimental and simulated fuel concentration times 10 for clarity.

Figure 26. $0.1 \%$ cyclohexane oxidation at 10 atm, $\varphi=1.5, \tau=0.5 \mathrm{sec}$ in a jet stirred reactor. Experimental (points) $)^{12}$ and model predicted mole fraction for some of the species reported in the experimental studies. Experimental and simulated fuel concentration times 5 for clarity.

\section{FIGURES}

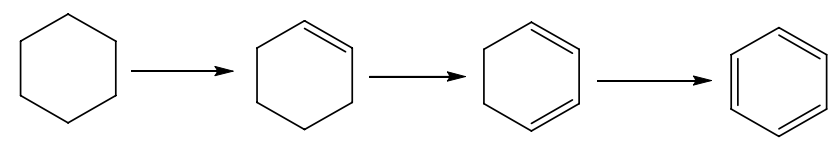

Figure 1. The formation of benzene from cyclohexane, via cyclohexene and cyclohexa-1,3-diene.

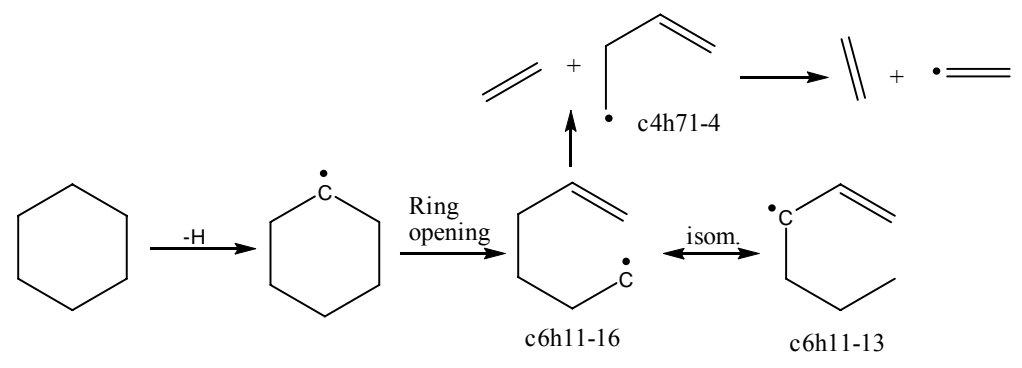

Figure 2. An example of a ring opening reaction, followed by alkyl radical isomerisation. 


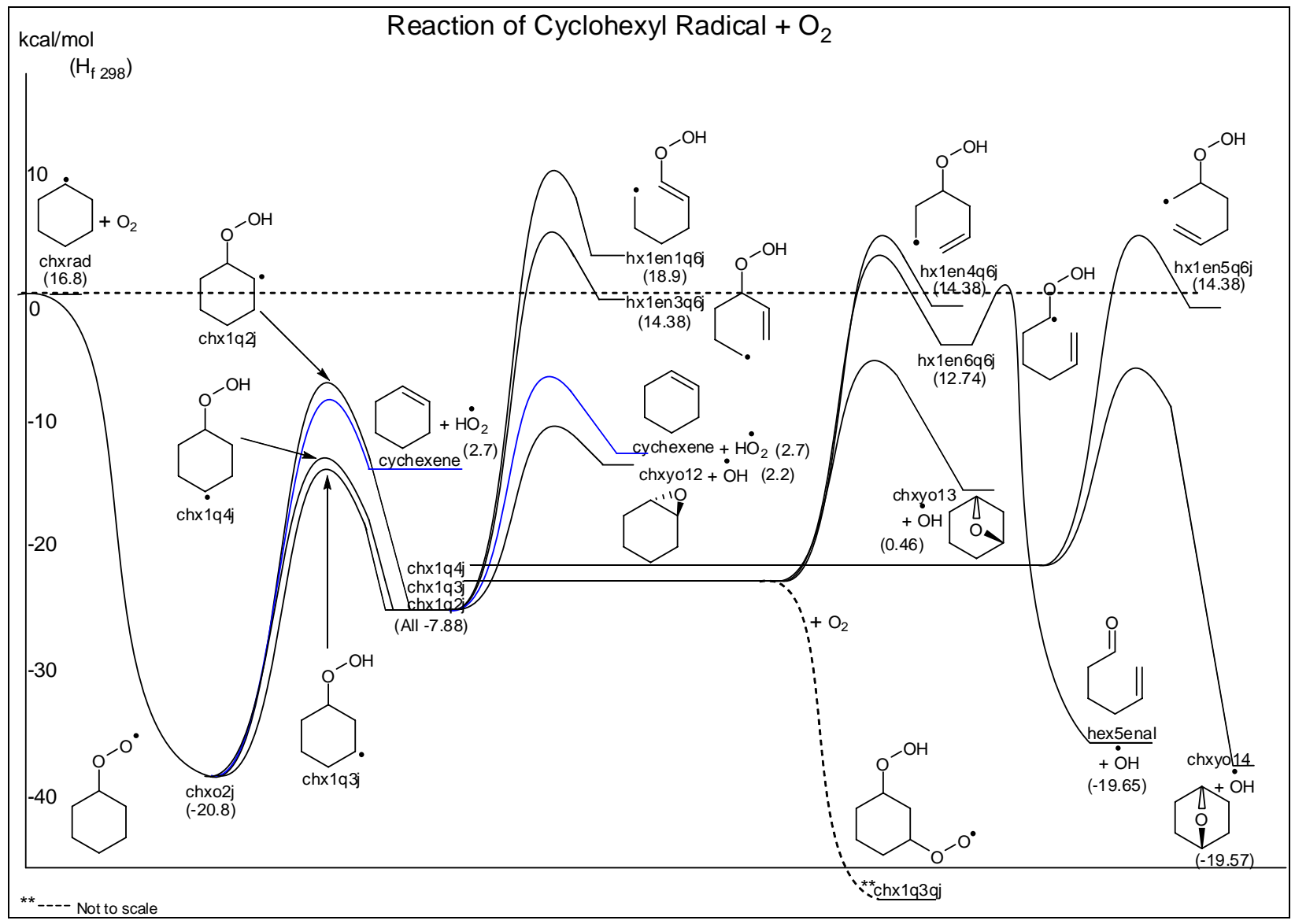

Figure 3. Potential energy diagram for the reaction of cyclohexyl radical (R) with $\mathrm{O}_{2}$, using thermodynamic properties determined in this work.

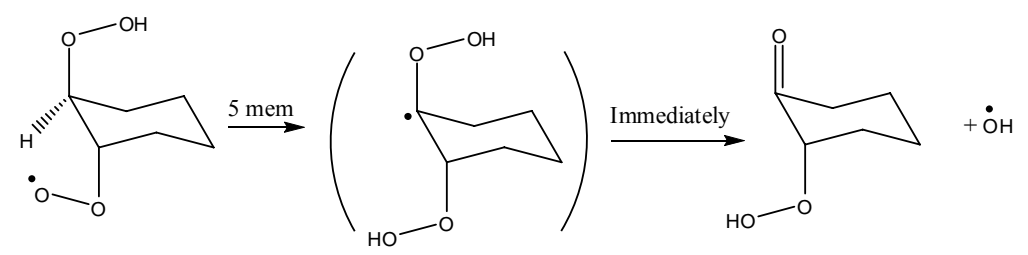

Figure 4. An example of the more conventional $\mathrm{O}_{2} \mathrm{QOOH}$ isomerisation leading to carbonylhydroperoxide $+\mathrm{OH}$. 


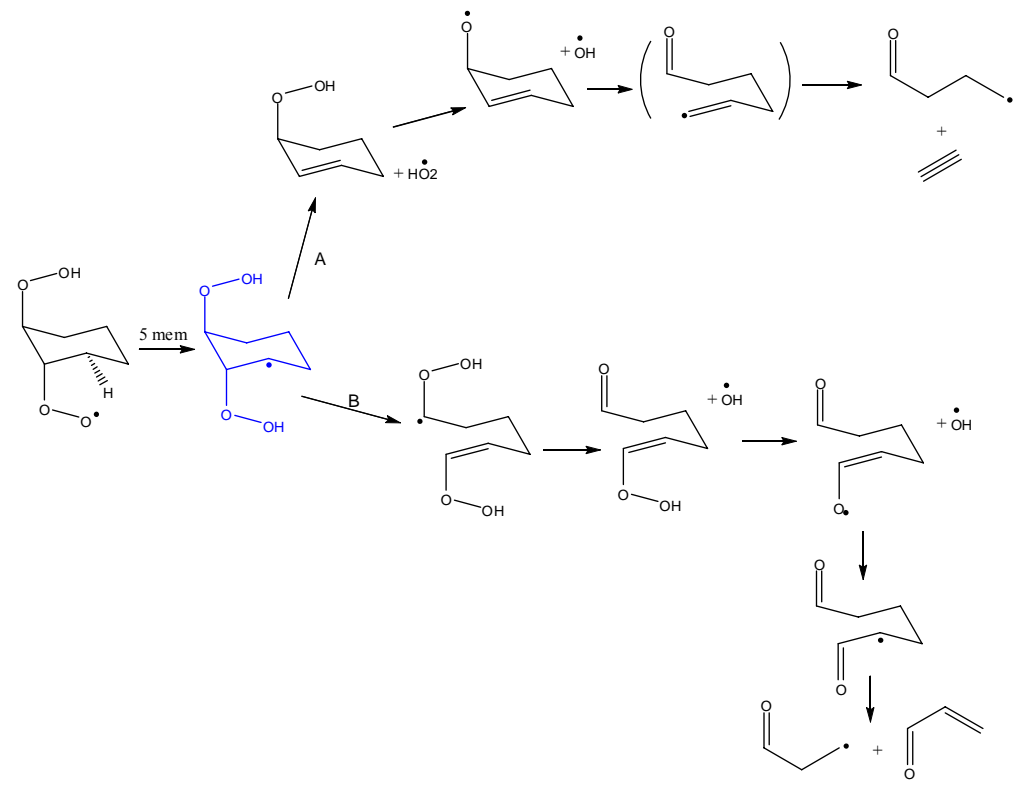

Figure 5. An example of the type of 'alternative' $\mathrm{O}_{2} \mathrm{QOOH}$ isomerisations permitted in this work. Example shows 5-membered transition state and 2 possible routes of decomposition.

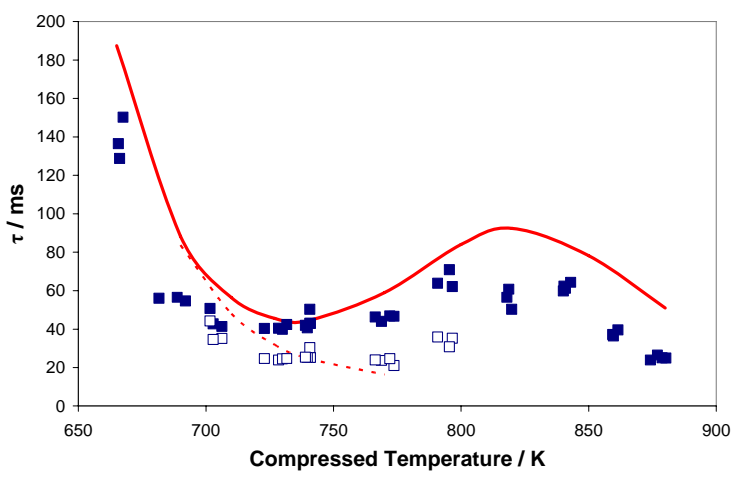

Figure 6. Experimental ${ }^{11}$ (points), pressure range 7-9 atm from a rapid compression machine investigation and model predicted ignition delay times (line) at 8 atm. Open symbols and dashed lines correspond to cool flame ignition measurements. 


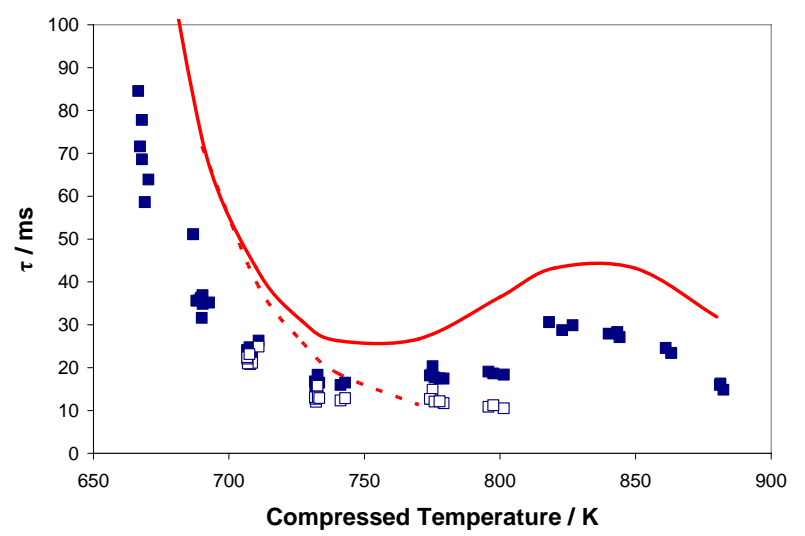

Figure 7. Experimental ${ }^{11}$ (points), pressure range 11-14 atm from a rapid compression machine investigation and model predicted ignition delay times (line) at $12.5 \mathrm{~atm}$. Open symbols and dashed lines correspond to cool flame ignition measurements.

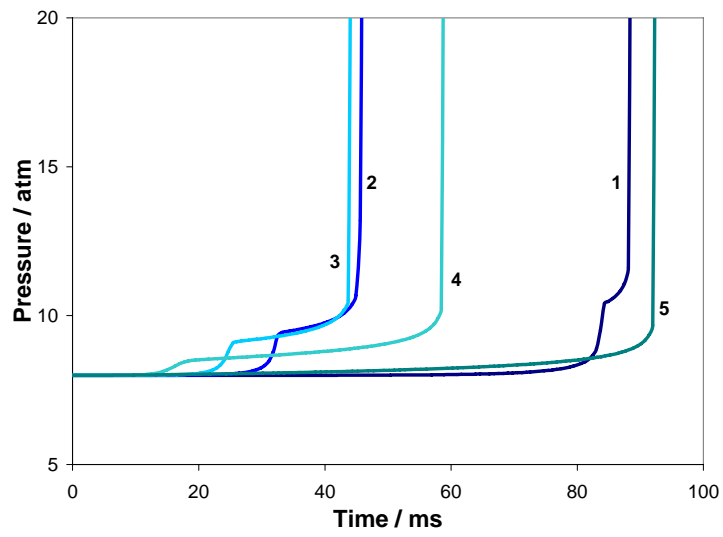

Figure 8. Model predicted pressure-time profiles for rapid compression machine experiments, depicting NTC behavior and the appearance and disappearance of cool flame phenomena. Curves correspond to the following end of compression temperatures: $1=690 \mathrm{~K}, 2=727 \mathrm{~K}, 3=$ $740 \mathrm{~K}, 4=770 \mathrm{~K}$ and $5=820 \mathrm{~K}$. 


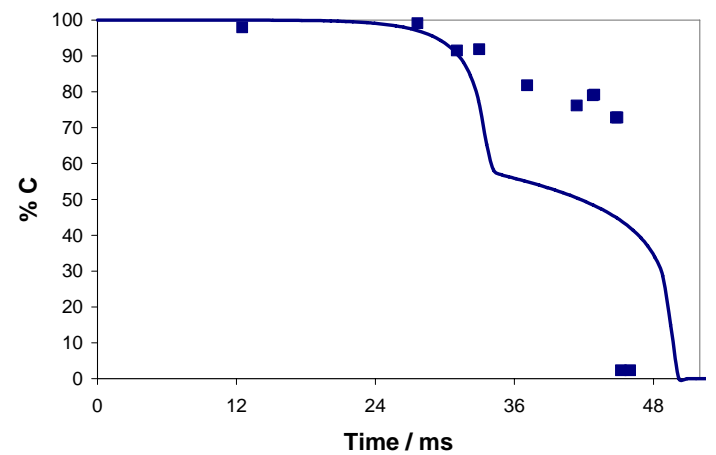

Figure 9. Comparison of cyclohexane consumption profile at $7.4 \mathrm{~atm}, \mathrm{~T}=727 \mathrm{~K}$ in the $\mathrm{RCM}$, experimental (points), model predicted (line). Time is the time after the end of compression.

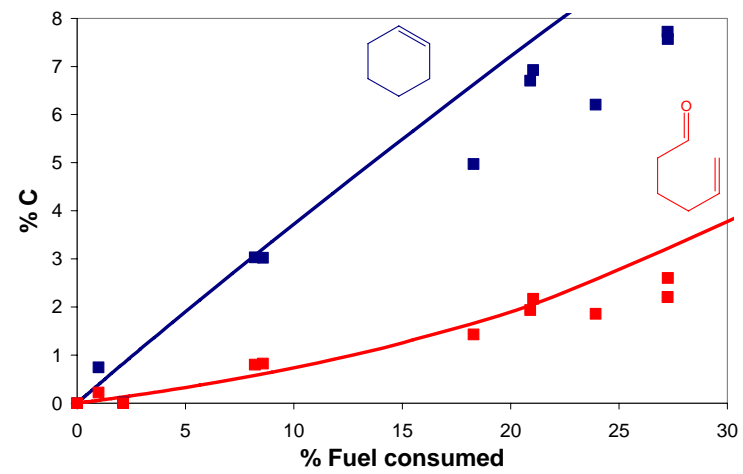

Figure 10. Species profile of cyclohexene in RCM (navy blue, experimental (points), model (lines)) and hex5enal (red, experimental (points), model (lines)).

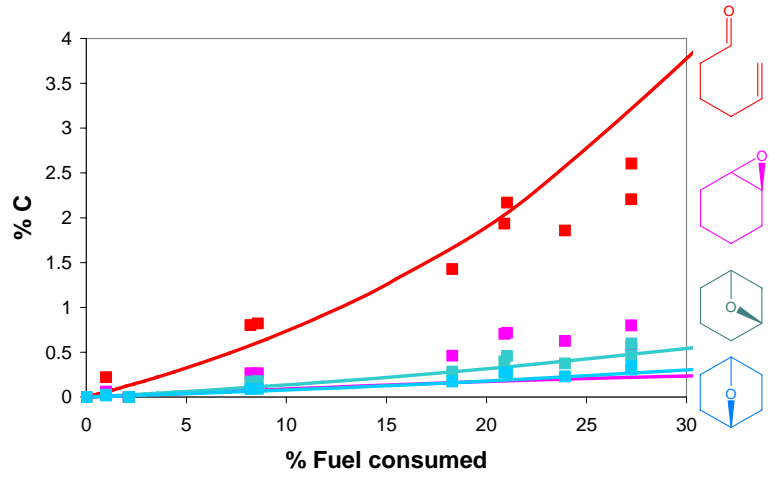


Figure 11. Species profile of hex5enal in RCM (red, experimental (points), model (lines)), 1,2epoxycyclohexane (magenta, experimental (points), model (lines)), 1,3-epoxycyclohexane (green, experimental (points), model (lines)), and 1,4-epoxycyclohexane (blue, experimental (points), model (lines)).

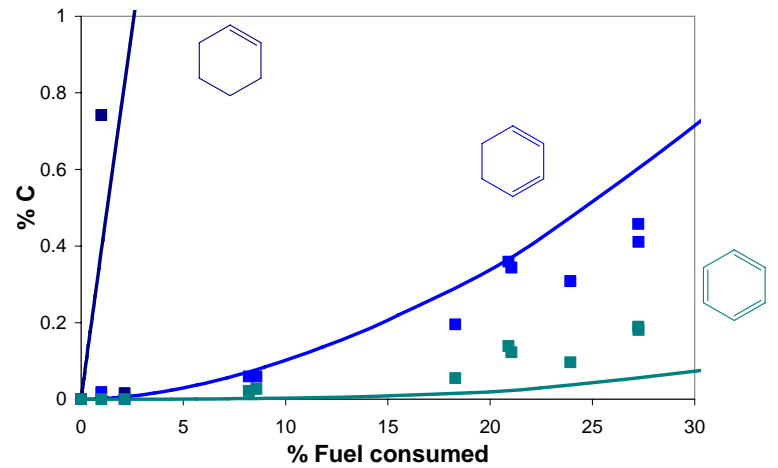

Figure 12. Species profile of the soot precursors in RCM: cyclohexene (navy blue, experimental (points), model (lines)), cyclohexa-1,3-diene (blue, experimental (points), model (lines)) and benzene (green, experimental (points), model (lines)).

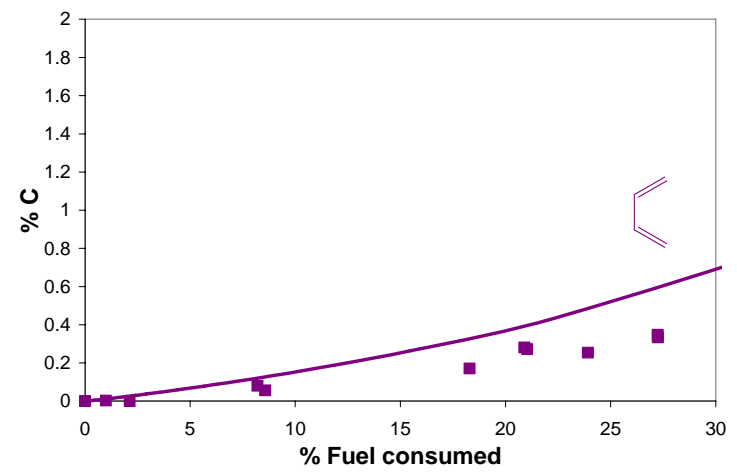

Figure 13. Species profile of 1,3-Butadiene in RCM (burgundy, experimental (points), model (lines)). 


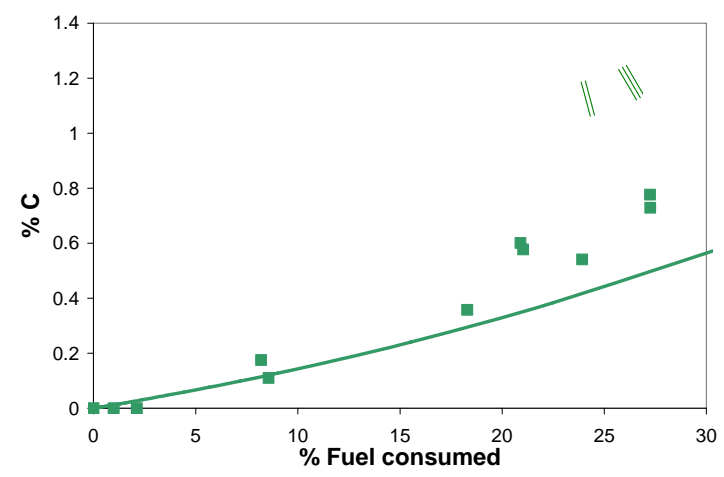

Figure 14. Species profile of ethene and ethyne (combined) in RCM (green, experimental (points), model (lines)).

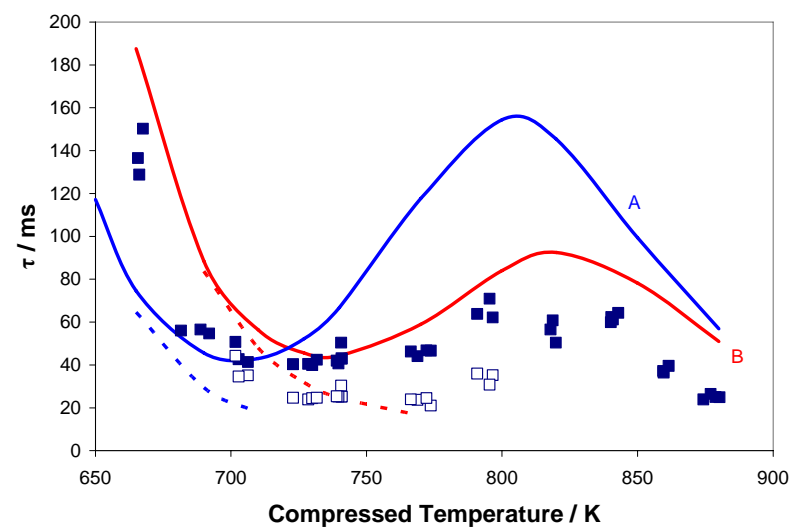

Figure 15. Comparing the performance of the mechanism used in this work when Ea for 'alternative' $\mathrm{O}_{2} \mathrm{QOOH}$ reaction class is varied: Experimental (points), pressure range 7-9 atm and model predicted ignition delay times (lines) at 8 atm. A) Ea based on analogous cyclic alkylperoxy isomerisations, B) Ea as in A but with reduction of $3 \mathrm{kcal} \mathrm{mol}^{-1}$. Open symbols and dashed lines correspond to cool flame ignition measurements. 


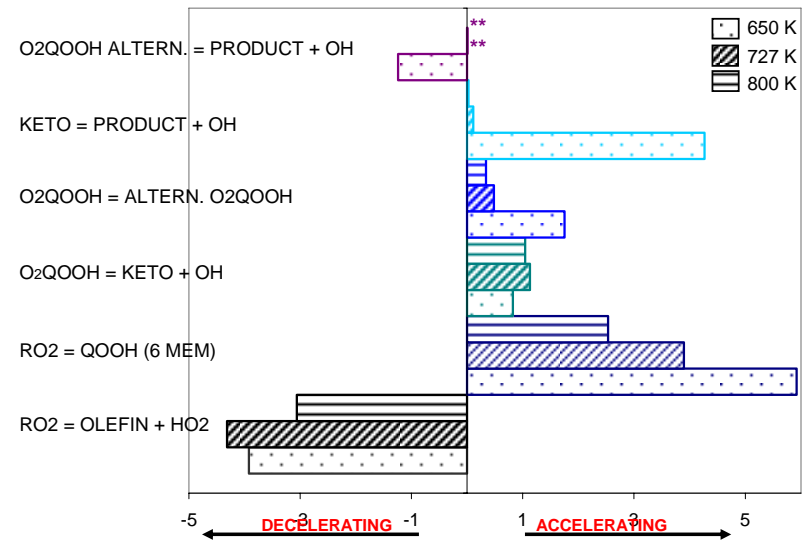

Figure 16. Sensitivity analysis for reactivity profile A in Figure 15, where Ea of 'alternative' $\mathrm{O}_{2} \mathrm{QOOH}$ paths is $3 \mathrm{kcal} \mathrm{mol}^{-1}$ higher than that for $\mathrm{O}_{2} \mathrm{QOOH}$ forming carbonylhydroperoxide. **Corresponds to negligible sensitivity.

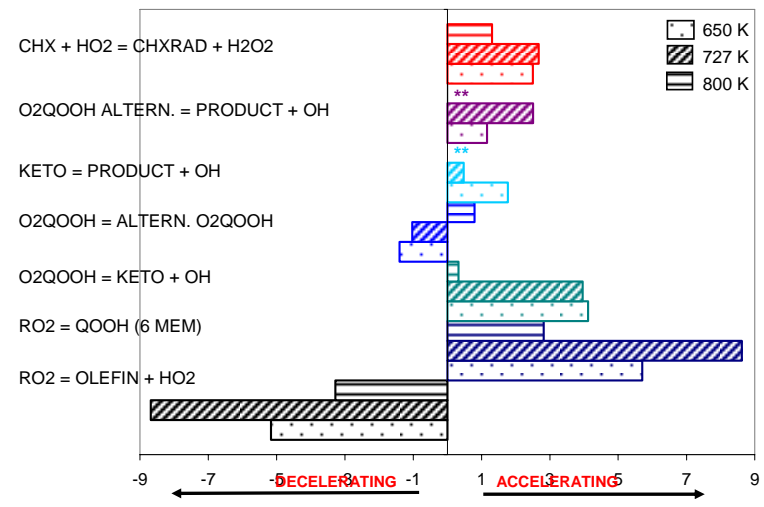

Figure 17. Sensitivity analysis for reactivity profile B in Figure 15, where Ea of 'alternative' $\mathrm{O}_{2} \mathrm{QOOH}$ paths is the same as that for $\mathrm{O}_{2} \mathrm{QOOH}$ forming carbonylhydroperoxide. **Corresponds to negligible sensitivity at $800 \mathrm{~K}$ for two of the reaction classes considered in the sensitivity analysis. 


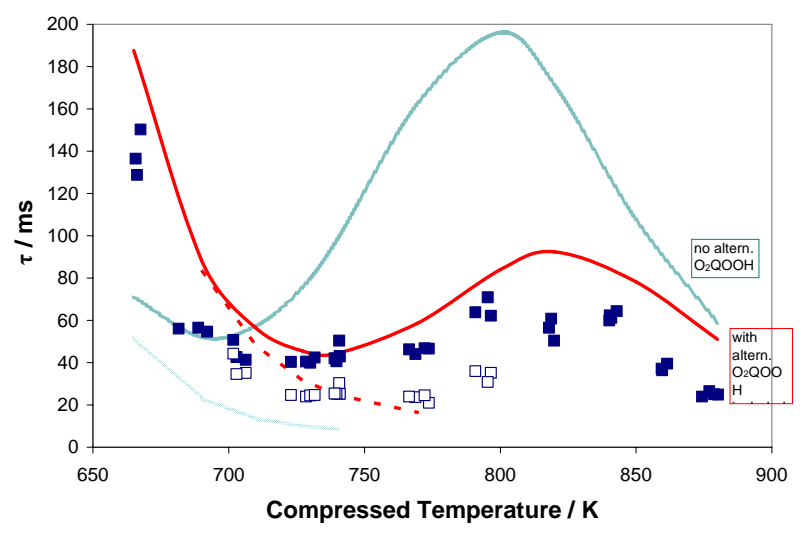

Figure 18. Experimental (points), pressure range 7-9 atm and model predicted ignition delay times (lines) at $8 \mathrm{~atm}$. Red line is the version of the mechanism containing 'alternative' $\mathrm{O}_{2} \mathrm{QOOH}$ pathways, green line is that with these species and reactions completely removed from the mechanism. Open symbols and dashed lines correspond to cool flame ignition measurements.

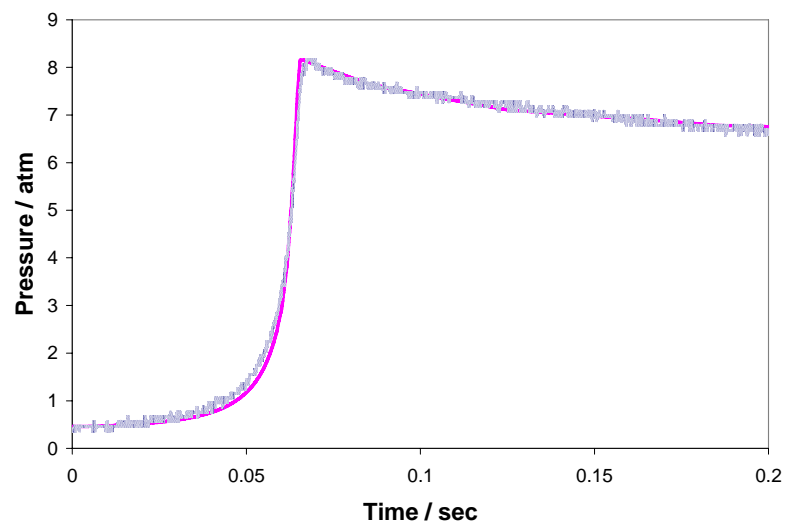

Figure 19. Experiment pressure-time data ${ }^{52}$ from the RCM (dashed navy blue lines). Pressuretime profile obtained using volume history generated in this work (solid magenta line). Mixture conditions as defined for (4) in Table 4, using an unreactive mechanism (no reactions), pi $=350$ torr, $\mathrm{Ti}=351 \mathrm{~K}$, Experimental $\mathrm{Tc}=737 \mathrm{~K}$, Predicted $\mathrm{Tc}=736.5 \mathrm{~K}$. 


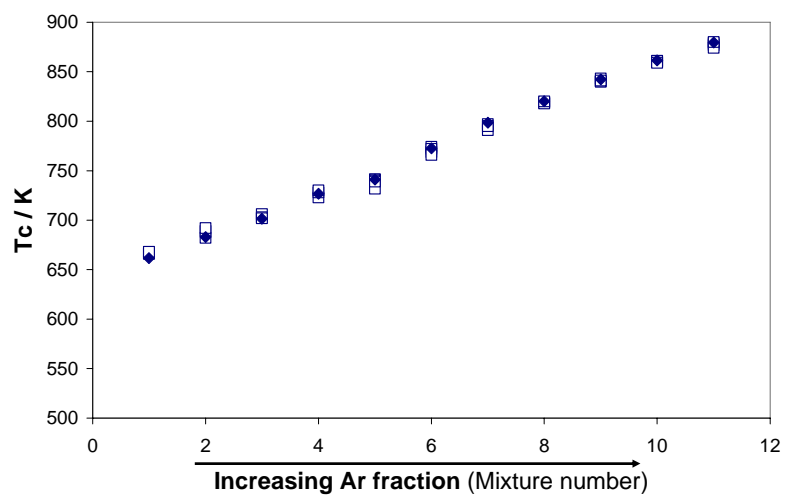

Figure 20. Compressed gas temperature prediction using volume history profile generated in this work (solid symbol) versus experimental compressed gas temperature (open symbol). Mixture composition is according to Table 4. Model is using a mechanism where no reactions are allowed. For both model and experiment $\mathrm{Ti}=354 \mathrm{~K}$ and $p i=350$ torr.

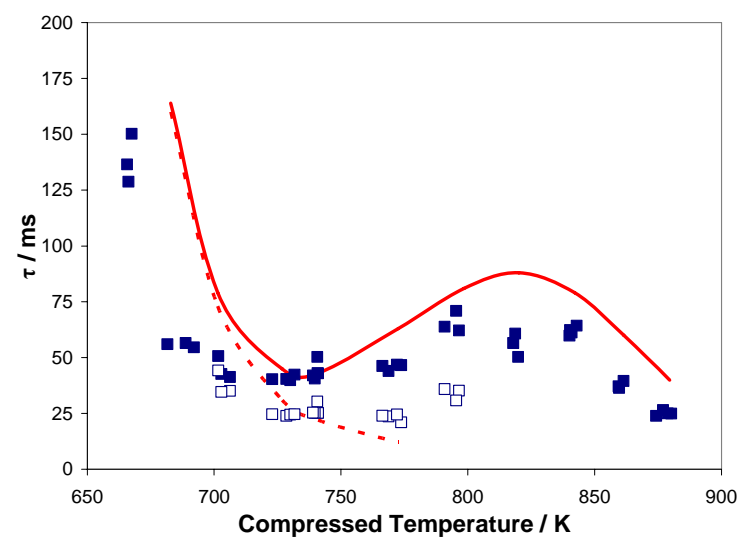

Figure 21. Experimental (points), pressure range 7-9 atm and model with heat loss predicted ignition delay times (lines). Open symbols and dashed lines correspond to cool flame ignition measurements. 
(a)

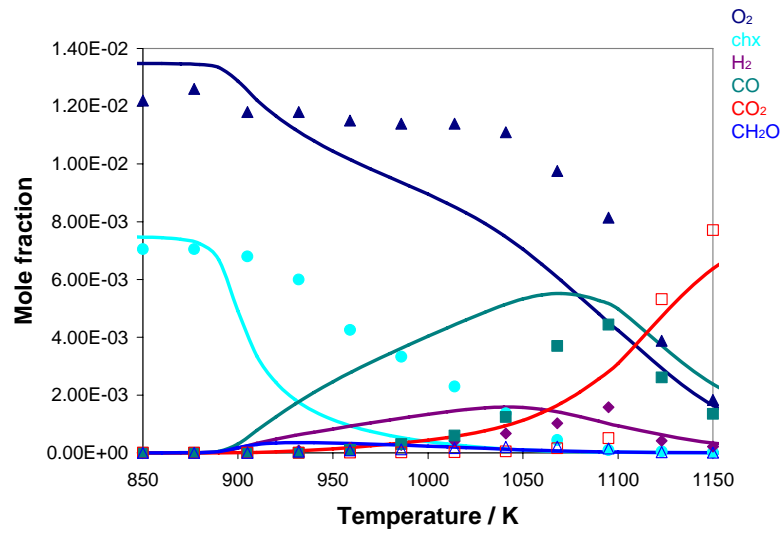

(b)

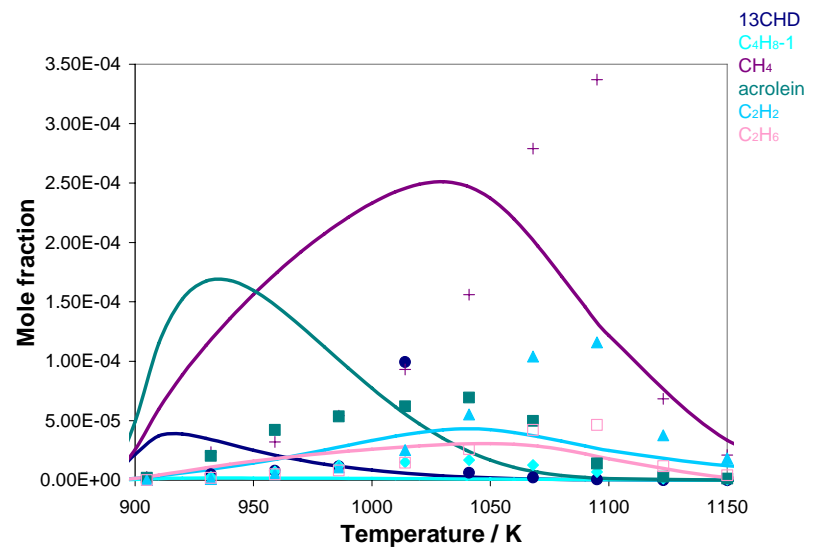

(c)

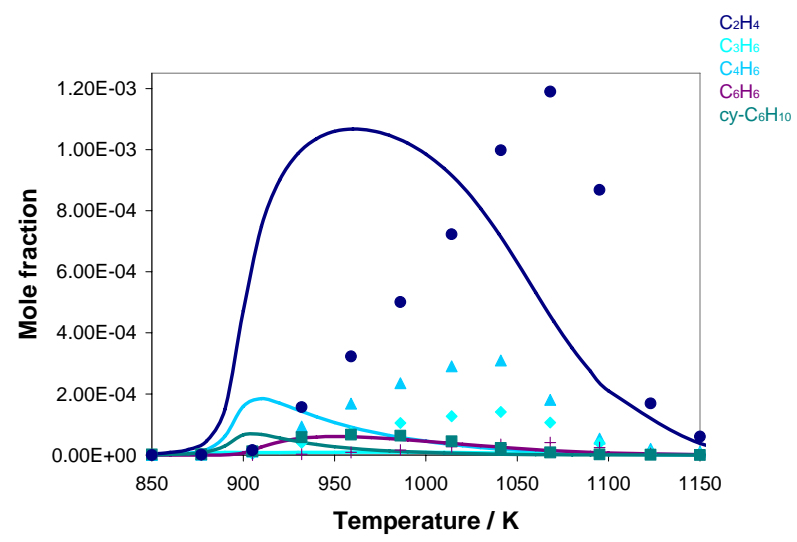


Figure 22. $0.15 \%$ cyclohexane oxidation at $2 \mathrm{~atm}, \varphi=1.0, \tau=0.1 \mathrm{sec}$ in a jet stirred reactor. Experimental (points) ${ }^{13}$ and model predicted mole fraction for some of the species reported in the experimental study. Experimental and simulated fuel concentration times 5 for clarity.

(a)

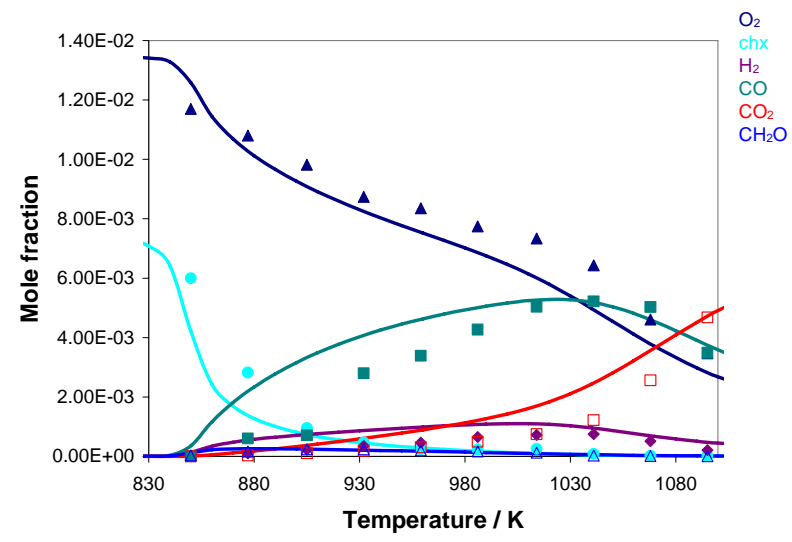

(b)

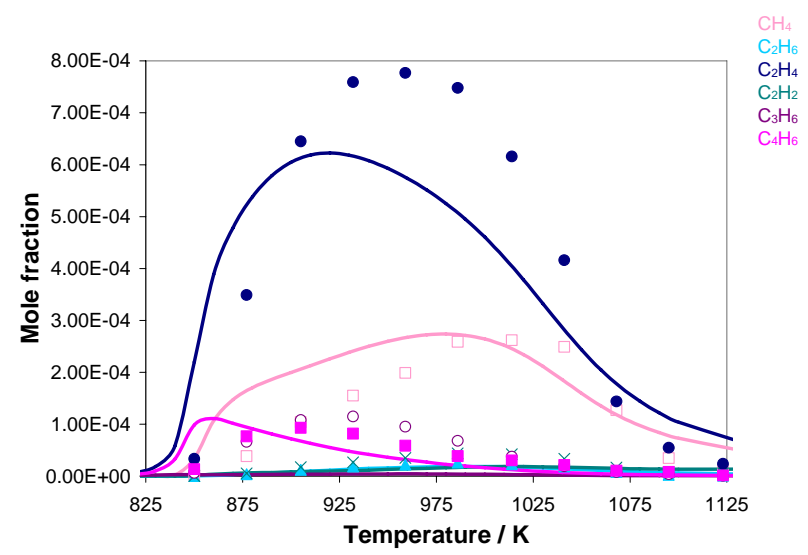

(c) 


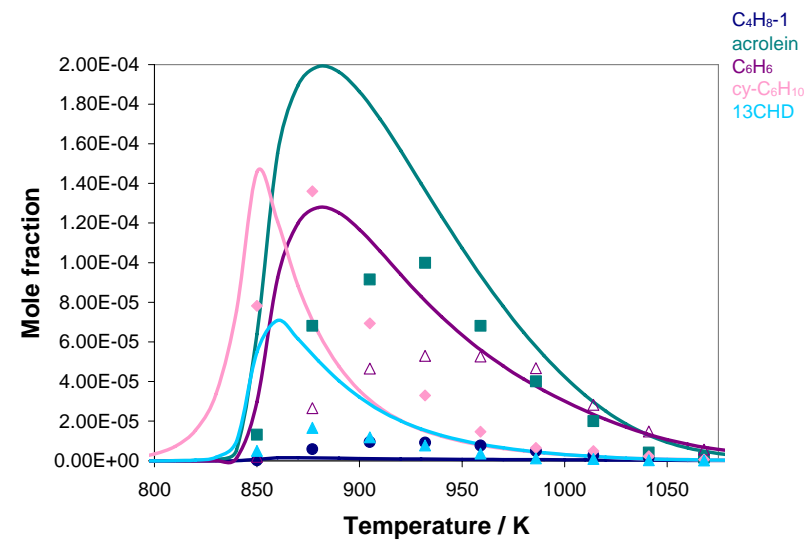

Figure 23. $0.15 \%$ cyclohexane oxidation at $5 \mathrm{~atm}, \varphi=1.0, \tau=0.25 \mathrm{sec}$ in a jet stirred reactor. Experimental (points) ${ }^{55}$ and model predicted mole fraction for some of the species recorded in the experimental study. Experimental and simulated fuel concentration times 5 for clarity.

(a)

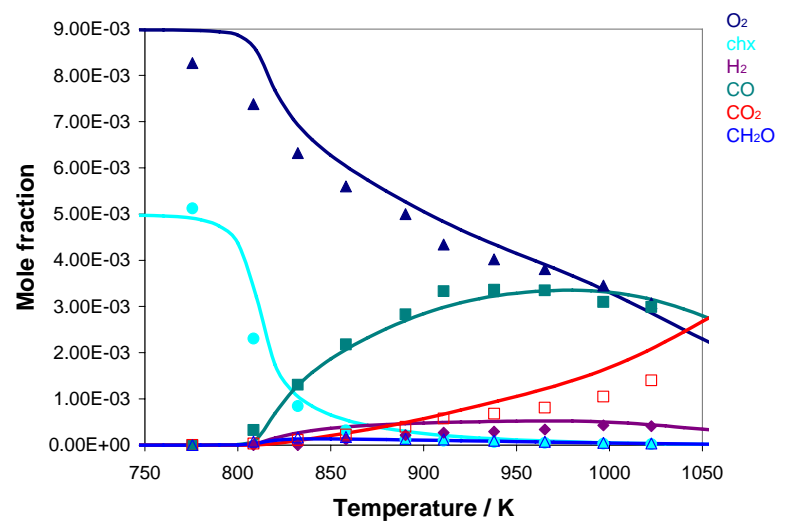

(b) 


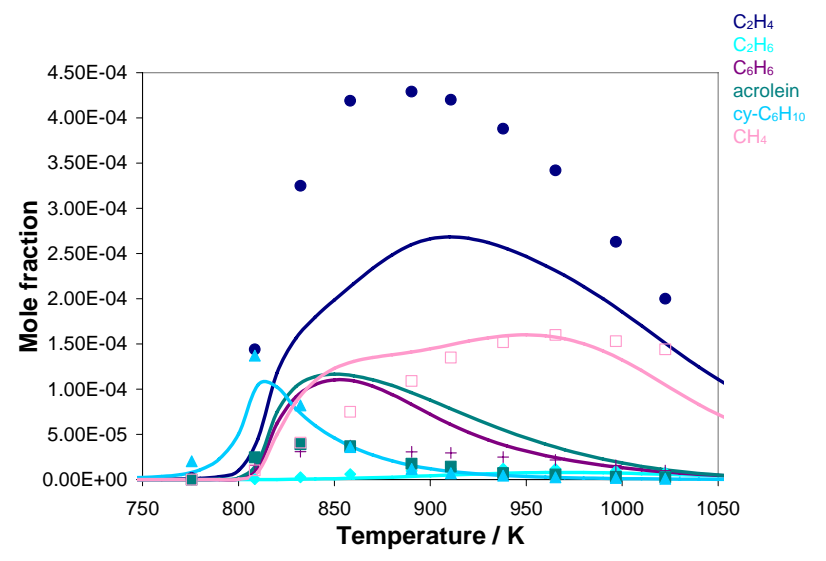

(c)

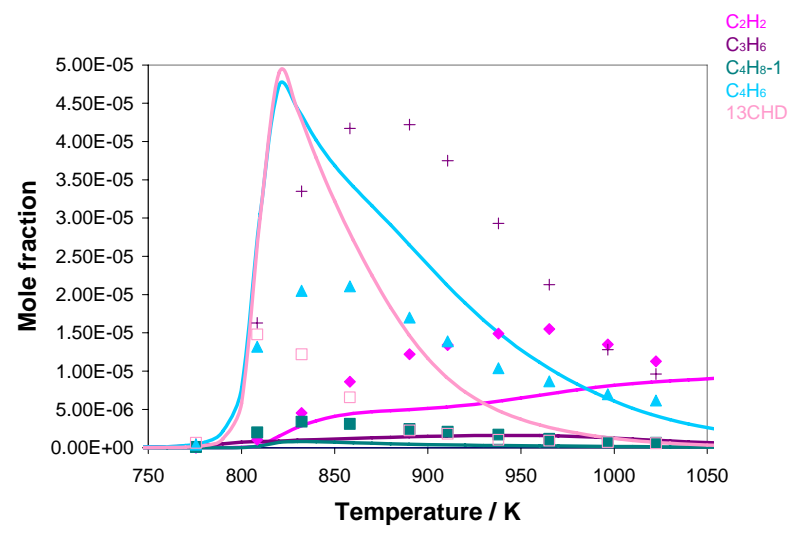

Figure 24. $0.1 \%$ cyclohexane oxidation at $10 \mathrm{~atm}, \varphi=1.0, \tau=0.5 \mathrm{sec}$ in a jet stirred reactor. Experimental (points) ${ }^{12,13}$ and model predicted mole fraction for some of the species reported in both experimental studies. Experimental and simulated fuel concentration times 5 for clarity.

(a) 


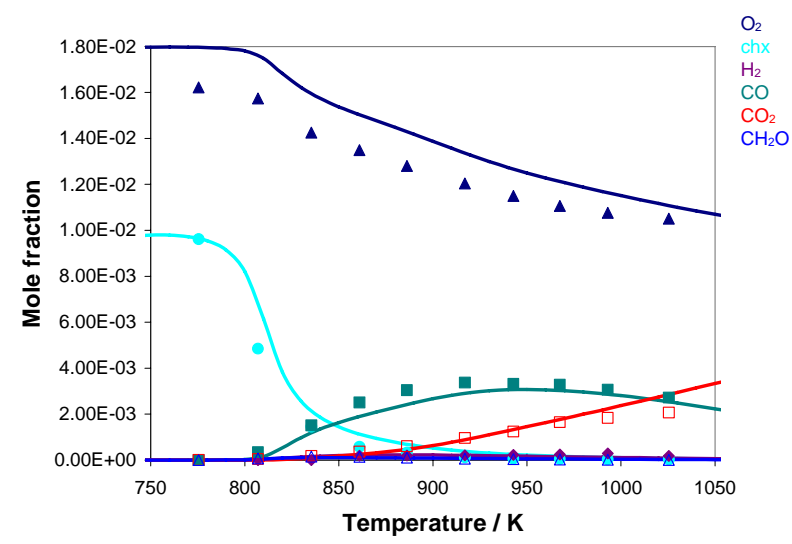

(b)

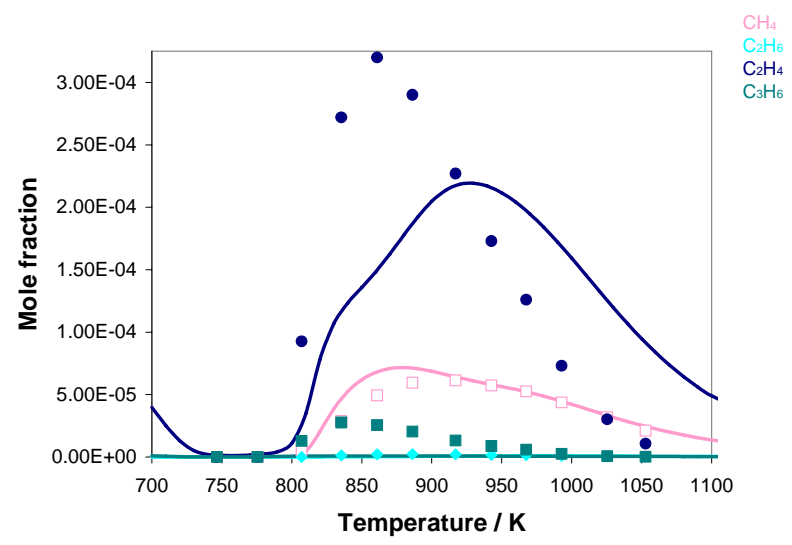

(c)

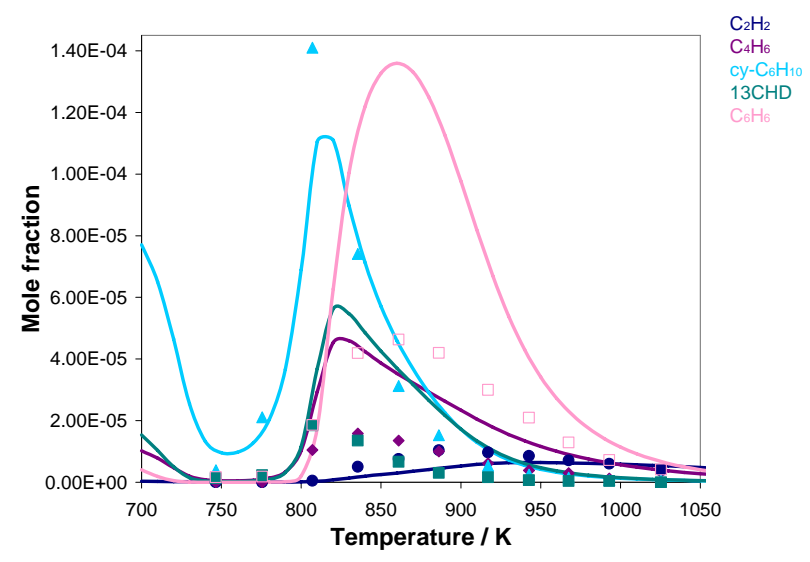


Figure 25. $0.1 \%$ cyclohexane oxidation at $10 \mathrm{~atm}, \varphi=0.5, \tau=0.5 \mathrm{sec}$ in a jet stirred reactor. Experimental (points) ${ }^{12}$ and model predicted mole fraction for some of the species reported in the experimental studies. Experimental and simulated fuel concentration times 10 for clarity.

(a)

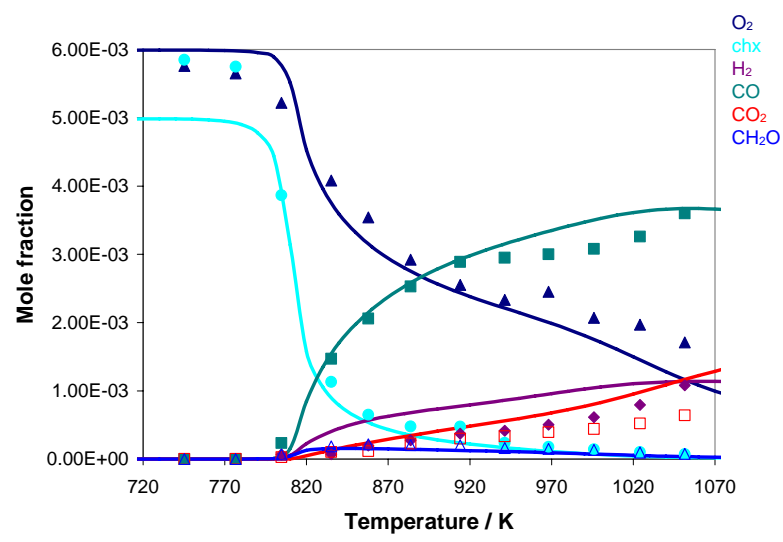

(b)

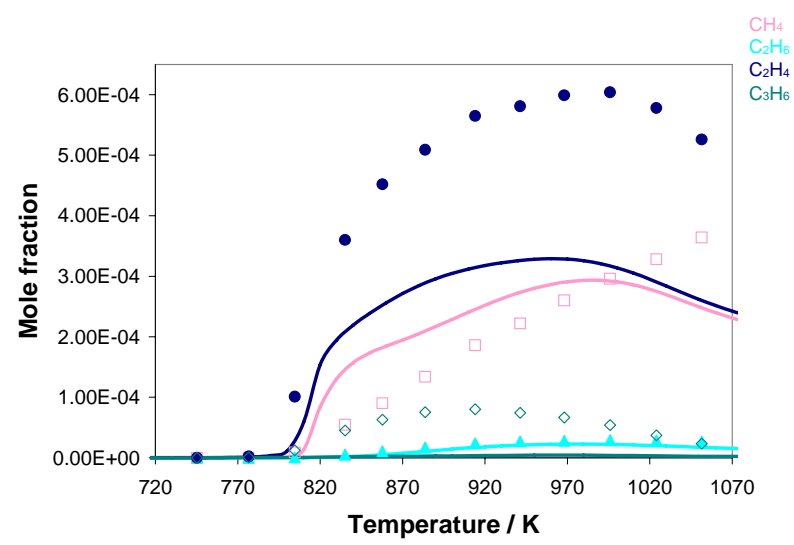

(c) 


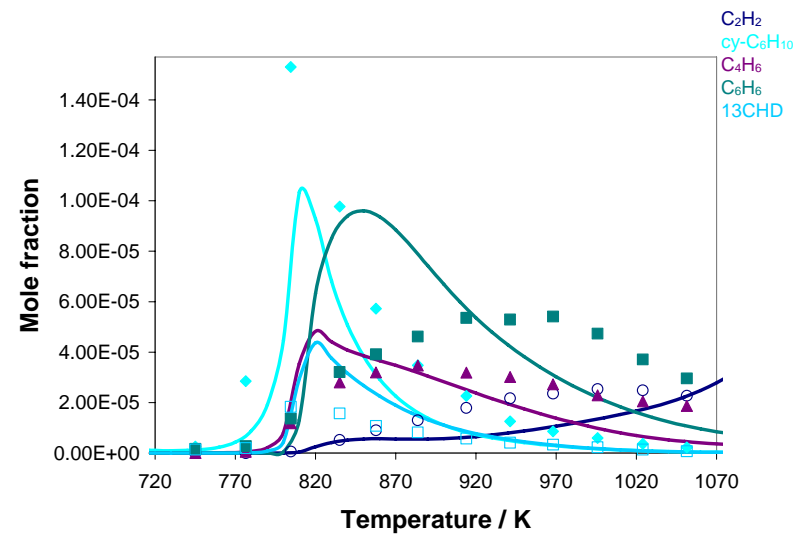

Figure 26. $0.1 \%$ cyclohexane oxidation at $10 \mathrm{~atm}, \varphi=1.5, \tau=0.5 \mathrm{sec}$ in a jet stirred reactor. Experimental (points) ${ }^{12}$ and model predicted mole fraction for some of the species reported in the experimental studies. Experimental and simulated fuel concentration times 5 for clarity. 